\title{
Perceptions of blue-green and grey infrastructure as climate change adaptation strategies for urban water resilience
}

\author{
Emily C. O'Donnell, Simon N. Gosling, Noelwah R. Netusil, \\ Faith Ka Shun Chan and Nanco J. Dolman
}

\begin{abstract}
Blue-Green Infrastructure (BGI, including swales, green roofs, and wetlands) plays an important role in reducing vulnerability to climate change risks such as flooding, heat stress, and water shortages, while enhancing urban environments and quality of life for citizens. Understanding the perceptions that professional stakeholders have of BGI is fundamental in addressing barriers to implementation. A novel application of the Implicit Association Test (IAT) is developed to investigate and compare implicit (unconscious) perceptions of bluegreen and grey infrastructure with explicit (conscious) attitudes. This is the first time an IAT about BGI has focused on professional stakeholders. Blue-green and grey infrastructure are perceived positively by the sample population. Overall, respondents implicitly and explicitly prefer BGI to grey infrastructure, and regard it as safer, tidier, more attractive, useful, valuable, and necessary. The individual positive explicit perceptions of grey infrastructure, nonetheless, suggest that integrated blue-green and grey systems may be preferable for professional stakeholders to incorporate into water management and climate change adaptation strategies.
\end{abstract}

Keywords: Blue-Green Infrastructure, Implicit Association Test, perceptions, grey infrastructure, climate change, adaptation, stakeholders, attitudes, flooding, urban water management.

Notes on the authors: see end of article.

(C) The author(s) 2021. This is an open access article licensed under a

Creative Commons Attribution-NonCommercial-NoDerivs 4.0 Unported License 


\section{Introduction}

Cities around the world face the challenge of adapting to the impacts of climate change, including more frequent and intense rainfall events, droughts, and heatwaves (IPCC 2014, Arnell et al. 2016, Guerreiro et al. 2018). The sustainable management of water resources is also crucial for urban climate resilience (Özerol et al. 2020). The form and function of cities intensifiy climate change impacts (Carter et al. 2018): urban development and consequential expansion of hard surfacing, for example, result in the loss of natural blue and green spaces that previously contributed to reducing flood risk through infiltration, attenuation, conveyance, and/or storage (O'Donnell $\&$ Thorne 2020). Flooding is a major risk for urban environments: for example, it is the greatest risk to infrastructure in the UK from climate change (Dawson et al. 2018). The increase in hydrological extremes seen across the globe as a result of humaninduced climate change (Gudmundsson et al. 2021) has led to many international cities developing adaptation strategies to reduce the impacts of climate change while maintaining (or enhancing) healthy environments, quality of life for citizens, and economic activity (City of Rotterdam 2013, City of Melbourne 2017, Scottish Government 2019). In the European Union these may include strategies for smart specialisation whereby unique opportunities for development and growth are identified based on assets, resources, and specific socio-economic challenges in different cities, regions, and countries (European Commission 2020), achieving the aim of cohesion policy by promoting a better link between the production of new knowledge stemming from innovation and investment, and its application to new projects and services (D'Adda et al. 2020). Climate change adaptation is increasingly framed as an opportunity to improve liveability and well-being in cities (Aylett 2015). Progressively more local governments are including climate resilience within broader goals to improve quality of life in cities (Hölscher et al. 2019) and meet the Sustainable Development Goals (SDGs), particularly around good health and well-being (SDG3), clean water and sanitation (SDG6), and sustainable cities and communities (SDG11).

The functionality provided by urban green (and blue) space is increasingly important in a changing climate (Gill et al. 2007). Blue-Green Infrastructure (BGI), often referred to in the context of flood and water management, is defined by the use of natural and designed blue and green components to mimic and/or enhance natural hydrological cycle processes of infiltration, evapotranspiration, and reuse (Novotny et al. 2010). BGI assets, including swales, rain gardens, green roofs, wetlands, street trees, ponds, and re-naturalised and de-culverted rivers, are designed to turn 'blue' (or 'bluer') during rainfall events in order to reduce urban flood risk. BGI, like Nature-Based Solutions (NBS) and Sustainable Drainage Systems (SuDS), offers a multifunctional approach that can further reduce vulnerability to other climate change 
risks, such as heat stress, water shortages, and air pollution (Demuzere et al. 2014). Despite extensive evidence of the multiple benefits of BGI, and provision of ecosystem services (e.g., Hansen \& Pauleit 2014, Fenner 2017, Alves et al. 2019a, Paulin et al. 2020), a range of institutional, socio-political, and technical barriers limit widespread adoption (Brown \& Farrelly 2009, O’Donnell et al. 2017).

Understanding the myriad perceptions that professional city stakeholders hold towards different types of BGI in the public realm is fundamental in addressing the socio-political barriers to their implementation and ultimately delivering BGI projects that are accepted, supported, and desired (Suppakittpaisarn et al. 2019, O'Donnell et al. 2020a). Previous research into the perceptions of BGI has focused on residents and communities living alongside blue-green assets, and typically report stated preferences based on explicit, or self-reported measures such as questionnaires, interviews, and Likert-scale tests (e.g., Hayden et al. 2015, Derkzen et al. 2017, Wang et al. 2017, Everett et al. 2018, Williams et al. 2019). It is essential to supplement knowledge of public perceptions with an understanding of the attitudes of professionals working with blue-green and grey infrastructure, in order to understand challenges and opportunities, and to identify where changes in research foci, policy, and practice are needed for increased implementation of multifunctional BGI. Furthermore, these experts are trusted to develop BGI projects that deliver multiple benefits beyond urban water management, founded on their perceptions of what constitutes a 'good' design (Suppakittpaisarn et al. 2019). The need to understand their preferences, and understand how they may differ from public perceptions, is of paramount importance.

Investigations into the perceptions of blue-green and grey infrastructure held by professional stakeholders, to date, have used explicit measures. As an example, Shandas et al. (2019) explored the social, political, and biophysical opportunities and challenges of Green Stormwater Infrastructure (GSI) systems through focus groups with municipal managers in Portland, Oregon, and Clark County, Washington, USA. Miller and Montalto (2019) used a structured online survey to investigate the range of ecosystem services that New York City practitioners attribute to different types of Green Infrastructure (GI), ultimately inferring which types of GI are most desirable to professional stakeholders and why. While designers' and laypeople's preferences for different categories of GSI were found to be similar, Suppakittpaisarn et al. (2019) identified significant differences between preferences for bioretention basins and green roofs.

The explicit attitude measures employed in these examples assume that participants know and can articulate their beliefs (Schultz et al. 2004) and have an internalised concept of GSI/GI that they consciously base their attitudes on. While we expect professionals working with BGI to be able to articulate their explicit perceptions of blue-green and grey infrastructure, explicit attitude measures are also affected by 
self-presentation effects - that is, responses that attempt to convey information about oneself or a desired image of oneself to other people (Baumeister \& Hutton 1987) - that undermine their validity (Gregg \& Klymowsky 2013). Implicit attitude measures that are not consciously controlled (that is, are spontaneous) remove many of the external influences that affect explicit tests (Spence \& Townsend 2006), and provide insight into underlying or unspoken attitudes that may diverge from conscious attitudes (Greenwald \& Banaji 1995).

The Implicit Association Test (IAT) is widely used to reveal implicit attitudes by measuring the strengths of concept-attribute associations (Greenwald et al. 1998). The IAT is a computer-based methodology in which participants sort stimuli into pairings of contrasting target-concepts and evaluative attributes; the response time of different pairings is compared to determine implicit preferences. Participants match stimuli, either words or photographs (for example, Daisy or Caterpillar) with the appropriate concept (for example, Flower or Insect) as quickly as possible. Two concepts are then combined (Flower and Pleasant; Insect and Unpleasant). Implicit attitudes are calculated as the difference between the average response times for compatible trials (Flower and Pleasant; Insect and Unpleasant) and incompatible trials (Flower and Unpleasant; Insect and Pleasant).

Early IATs focused on controversial or sensitive topics, investigating implicit prejudices based on race, religious ethnicity, age, and nationality (e.g., Greenwald et al. 1998, Rudman et al. 1999). In the field of environmental research, IATs have been used to investigate perceptions of climate change (Beattie \& McGuire 2012), nuclear power (Siegrist et al. 2006, Truelove et al. 2014), implicit connectedness with nature (Schultz et al. 2004, Bruni \& Schultz 2010, Liu et al. 2019), and the influence of extreme weather on voting habits (Rudman et al. 2013). Implicit attitudes towards blue-green and grey infrastructure are not yet understood. In a novel application of the IAT, O'Donnell et al. (2020a) investigated and compared implicit and explicit perceptions of SuDS in public greenspace, based on a sample population of residents in Newcastle-upon-Tyne, UK $(n=193)$. Greenspace with and without SuDS were perceived positively by most respondents yet greenspace without SuDS was implicitly and explicitly preferred, and explicitly regarded as more attractive, tidier, and safer. 


\section{Study scope and rationale}

In this paper, we investigate and compare implicit and explicit perceptions of blue-green and grey infrastructure, measured by an IAT and feeling thermometers, ${ }^{1}$ respectively, of professionals with expertise in blue-green and grey infrastructure from a range of disciplinary backgrounds: for example, engineering, environmental management, implementation, landscape architecture and design, planning, and policy. The sample population is drawn from professionals engaging with the research project 'Developing new Blue-Green futures: multifunctional infrastructure to address water challenges', part of the British Academy programme on Tackling the UK's International Challenges (Blue-Green Futures 2019). This project explores how four international cities, at the forefront of BGI implementation in their respective countries (Newcastle, UK; Rotterdam, The Netherlands; Portland, Oregon, USA; and Ningbo, China), are tackling urban flood and water challenges and developing visions for Blue-Green urban futures, characterised by widespread implementation of multifunctional BGI that delivers multiple benefits for the environment, society, and economy (O'Donnell et al. 2021). For instance, Rotterdam is an international leader in aligning climate change adaptation, water management, and spatial planning to increase urban resilience to the impacts of climate change, while concurrently improving quality of life (Tillie \& van der Heijden 2016). Ningbo is a Chinese pilot city in the 'Sponge City Programme', tasked with integrating low-impact development and BGI with urban planning to mitigate flood risk, manage stormwater, improve water quality, and store water for future use (Jiang et al. 2017). Portland has invested widely in BGI over the last two decades to alleviate loadings on the piped infrastructure system, improve water quality, and manage flood risk (McPhillips \& Matsler 2018), and has one of the oldest and most successful GI programmes in the United States. Finally, risk management authorities in Newcastle are investing in combinations of blue-green and grey infrastructure to improve the city's resilience to future flooding while delivering social and environmental benefits from above-ground, attractive BGI systems (Amec Foster Wheeler 2016).

This geographically targeted investigation used purposive sampling (Tongco 2007) to select participants in the four cities and provide a breadth of experiences around blue-green and grey infrastructure. As a random sample of professional stakeholders was not taken, the findings are specific to the sample group. Limited sample sizes in each city preclude a comparison of perceptions in Newcastle, Ningbo, Portland, and Rotterdam (O'Donnell et al. 2021). Location is one of the many factors that could influence perceptions of BGI, as could awareness of purpose and function

${ }^{1} \mathrm{~A}$ visual scale that enables respondents to express their attitudes about a given subject by applying a numeric rating of their feelings (referred to as 'slider bars' in the USA). 
(Everett et al. 2018), broader environmental attitudes around climate change (Schultz et al. 2004), demographic factors, and how facilities are used within the public realm (Lamond \& Everett 2019). As these factors were not controlled, we rationalise that our data present general insight into perceptions of blue-green and grey infrastructure in the four cities, and recommend further investigation to uncover the influence that the aforementioned factors, including location, have on perceptions of BGI. We expect respondents to express positive explicit perceptions of BGI, owing to the expert knowledge they hold of the benefits of such approaches and their professional role in BGI strategy, planning, design, and implementation. To our knowledge, this is the first comparative study of the implicit and explicit perceptions that professional stakeholders have of blue-green and grey infrastructure, and, hence, presents a novel exploration of whether stated preferences for BGI align with unconscious perceptions. This research also contributes to the urban studies literature by providing the first insight into implicit perceptions of blue-green and grey infrastructure which play a key, but previously unexplored, role in influencing attitudes and behaviours around urban water management.

\section{Methods}

\section{Online surveys}

The sampling frame was professional stakeholders with expertise in BGI, stormwater management and/or climate change adaptation and mitigation, urban planning, design, and implementation. Participants were drawn from government organisations, private organisations (such as UK water companies or environmental consultancies), academia, and nonprofits (such as environmental charities and advocacy groups). Participants were recruited with a personalised email from the research team, and directed to the online survey. Forty-four participants were invited with 93 per cent ( $n=41)$ completing all questions (fourteen from Newcastle, and nine each from Ningbo, Rotterdam, and Portland). The survey took approximately 10 minutes to complete and was open from July 2019 until January 2020. Four identical surveys were launched: one using UK English, one US English, one in Dutch, and one in Chinese. As the IAT score was determined by response times to different pairings of target-concepts and evaluative attributes, it was imperative that respondents understood the instructions and that the words used were easy to visualise and unambiguously classifiable: hence, the need for four tests.

Participants read a participant information sheet and granted consent prior to completing the survey. Participants were first asked to read a definition of BGI to 
remove any ambiguities regarding the meaning of BGI in this study: 'Blue-green infrastructure (including swales, rain gardens, green roofs, wetlands, street trees, and ponds) is an approach to stormwater and flood risk management that uses vegetation and soils to enhance andlor mimic the natural hydrological cycle processes of infiltration, evapotranspiration and reuse.' They then completed the BGI feeling thermometers. Participants were next asked to read a definition of grey infrastructure: 'Traditional grey infrastructure refers to the human-engineered infrastructure used in conventional piped drainage, storage, water treatment and water supply systems. Infrastructure includes storm drains, storage tanks, culverts, subsurface pipes and combined sewer overflows. It typically refers to components of a centralised approach to water management.' They then completed the grey infrastructure feeling thermometers. Words were used instead of photographs in all tests in order to assess participants' internal understanding of blue-green and grey infrastructure and avoid introducing bias associated with image choice. Finally, participants completed the IAT (detailed subsequently).

\section{Explicit test: feeling thermometer}

Participants completed twelve thermometers to assess their feelings towards the safety, attractiveness, tidiness (or, for the US tests, how maintained they are perceived to be, which is more commonly used to describe the appearance of BGI), usefulness, valuableness, and necessity of blue-green and grey infrastructure (Appendix 1). Participants were instructed to click anywhere on the feeling thermometer to activate the slider and then drag the slider to the point that best reflects their feelings for each attribute. Scales ranged from 0 (for example, extremely unsafe) to 100 (extremely safe). As the initial starting position of the slider can influence the score-for example, respondents are more likely to select the slider's default value (Liu \& Conrad 2019) — the thermometers were designed without a default value. Clear instructions were given regarding how responses may be registered to reduce the risk of non-response (Roster et al. 2015). Averages of the six scores for BGI, and six scores for grey infrastructure, were calculated. Thermometer Difference (TD) scores were then calculated by subtracting the average BGI score from the average grey infrastructure score, and then normalised to a -2 to +2 scale to be consistent with the IAT D-score. Positive TD-scores indicate a preference for BGI, while negative scores reflect a preference for grey infrastructure.

\section{Implicit Association Test (IAT)}

The IAT method described by Greenwald et al. (1998) was followed and adapted to compare the automatic associations of blue-green and grey infrastructure. The appearance, instruction text, and programming of the new online IATs were based on 
the FreeIAT software (Meade 2009). Two types of stimuli were used: target-concepts and evaluative attributes. Target-concepts comprised seven words describing common types of BGI, and seven words describing grey infrastructure that are frequently used to manage stormwater (as shown in Table 1). The evaluative attributes consisted of seven positive and seven negative words that were originally selected from an online thesaurus as frequently used English-language synonyms for positive and negative concepts, and align with the attributes tested in the feeling thermometers. Of primary importance was that the words were easy to visualise and unambiguously classifiable as positive or negative; the actual selection of the words were of secondary importance as IAT scores typically reflect attitudes towards the overarching target-concepts rather than attitudes towards the individual exemplars of those concepts (De Houwer 2001). The implicit perceptions of safety, attractiveness, tidiness, usefulness, valuableness, and necessity (the six attributes tested in the feeling thermometers) are not directly assessed by the IAT but influence the resulting score.

Each IAT began with an introduction to the test and instructions for the participants (Appendix 2). The IAT consists of five blocks, each block containing twenty trials whereby each trial is associated with one stimulus, either a target-concept or evaluative attribute word (as shown in Table 2). Stimuli are randomly selected in all tests and then entered back into the selection processes: that is, a word could appear multiple times during one trial block. During the test, the randomly selected stimuli are presented, one at a time, in the centre of the screen and participants are asked to categorise each stimulus as quickly as possible using the left ('e') and right ('i') keys. The categories that the 'e' and ' $i$ ' keys represent are listed at the top of the screen, and are different in each block depending on the task description (for example, initial combined task), as illustrated in Table 2, with the solid black circles indicating allocation of the stimulus to either the left ('e') or right ('i') hand responses. For example, in Block 1 (initial target-concept discrimination), the participant would select the 'e' key if the stimulus was a word describing BGI, or the ' $i$ ' key if the word described grey infrastructure. Each stimulus is shown on the screen until a correct response (that is, the classification of the stimulus into the pre-selected categories), is registered. If an

Table 1. Words used in the Implicit Association Test (IAT); positive and negative evaluative attribute words, and target-concepts describing Blue-Green Infrastructure (BGI) and Grey infrastructure.

\begin{tabular}{ll}
\hline Positive words & Attractive, Clean, Healthy, Reliable, Safe, Useful, Valuable \\
Negative words & Dangerous, Dirty, Ugly, Unhealthy, Unreliable, Useless, Worthless \\
Blue-green infrastructure & Green roof, Green wall, Retention pond, Rain garden, Street tree, Swale, \\
& Wetland \\
Grey infrastructure & Combined sewer overflow, Culvert, Sewer, Storm drain, Subsurface pipe, \\
& Underground storage tank, Storm sewer \\
\hline
\end{tabular}


Table 2. Trial blocks in the Implicit Association Test (IAT). A solid black circle indicates allocation of a word to a left ('e') or right ('i') hand response. Modified after Greenwald et al. (1998).

\begin{tabular}{|c|c|c|c|c|c|}
\hline Block & 1 & 2 & 3 & 4 & 5 \\
\hline Task description & $\begin{array}{l}\text { Initial } \\
\text { target-concept } \\
\text { discrimination }\end{array}$ & $\begin{array}{l}\text { Evaluative } \\
\text { attributes } \\
\text { discrimination }\end{array}$ & $\begin{array}{l}\text { Initial } \\
\text { combined } \\
\text { task }\end{array}$ & $\begin{array}{l}\text { Reversed } \\
\text { target-concept } \\
\text { discrimination }\end{array}$ & $\begin{array}{l}\text { Reversed } \\
\text { combined } \\
\text { task }\end{array}$ \\
\hline Number of trials & 20 & 20 & 20 & 20 & 20 \\
\hline \multirow[t]{2}{*}{ Task instructions } & - Blue-green & - Positive & $\begin{array}{l}\text { - Blue-green } \\
\text { - Positive }\end{array}$ & - Blue-green & $\begin{array}{l}\text { Blue-green } \bullet \\
\text { Positive } \bullet\end{array}$ \\
\hline & Grey $\bullet$ & Negative $\bullet$ & $\begin{array}{l}\text { Grey } \bullet \\
\text { Negative } \bullet\end{array}$ & - Grey & $\begin{array}{l}\text { - Grey } \\
\text { - Negative }\end{array}$ \\
\hline Function & Practice & Practice & Test & Practice & Test \\
\hline
\end{tabular}

incorrect response is given (for example, by classifying a retention pond as grey infrastructure), a red ' $\mathrm{X}$ ' appears on the screen and the respondent must select the correct response key for the test to continue.

If participants find one of the combined tasks (blocks 3 or 5) easier (or faster to respond to) than the other, this means that they differentially associate target-concepts with evaluative attributes, which provides a measure of the implicit attitudinal difference among the target-concept categories. The IAT effect (called the 'difference' or $\mathrm{D}$-score) is the difference between the average response time across all trials in block 5 minus the average response time in block 3. D-scores were calculated using the improved scoring algorithm (Greenwald et al. 2003) adapted for five blocks rather than the original seven (O'Donnell et al. 2020a). D-scores range from -2 to +2 . Following standard practice, trials with response times $>10000 \mathrm{~ms}$ or $<300 \mathrm{~ms}$ for more than 10 per cent of their trials, were removed (Greenwald et al. 2003). The block mean of correct trials $+600 \mathrm{~ms}$ was added to trials initially answered incorrectly. A high D-score indicates that BGI was more closely associated with positive concepts and/or less closely associated with negative concepts, than grey infrastructure. D-scores between -0.2 and +0.2 are considered neutral, indicating no preference (Beattie \& McGuire 2012).

\section{Results}

The mean explicit TD-score was $0.66(\mathrm{SD}=0.52, n=41)$, indicating that the sample population has an explicit preference for BGI (Figure 1; all scores are provided in Appendix 3). TD-scores ranged from -0.36 to 1.55 . 78 per cent of the individual respondents expressed an explicit preference for BGI compared with 15 per cent who 


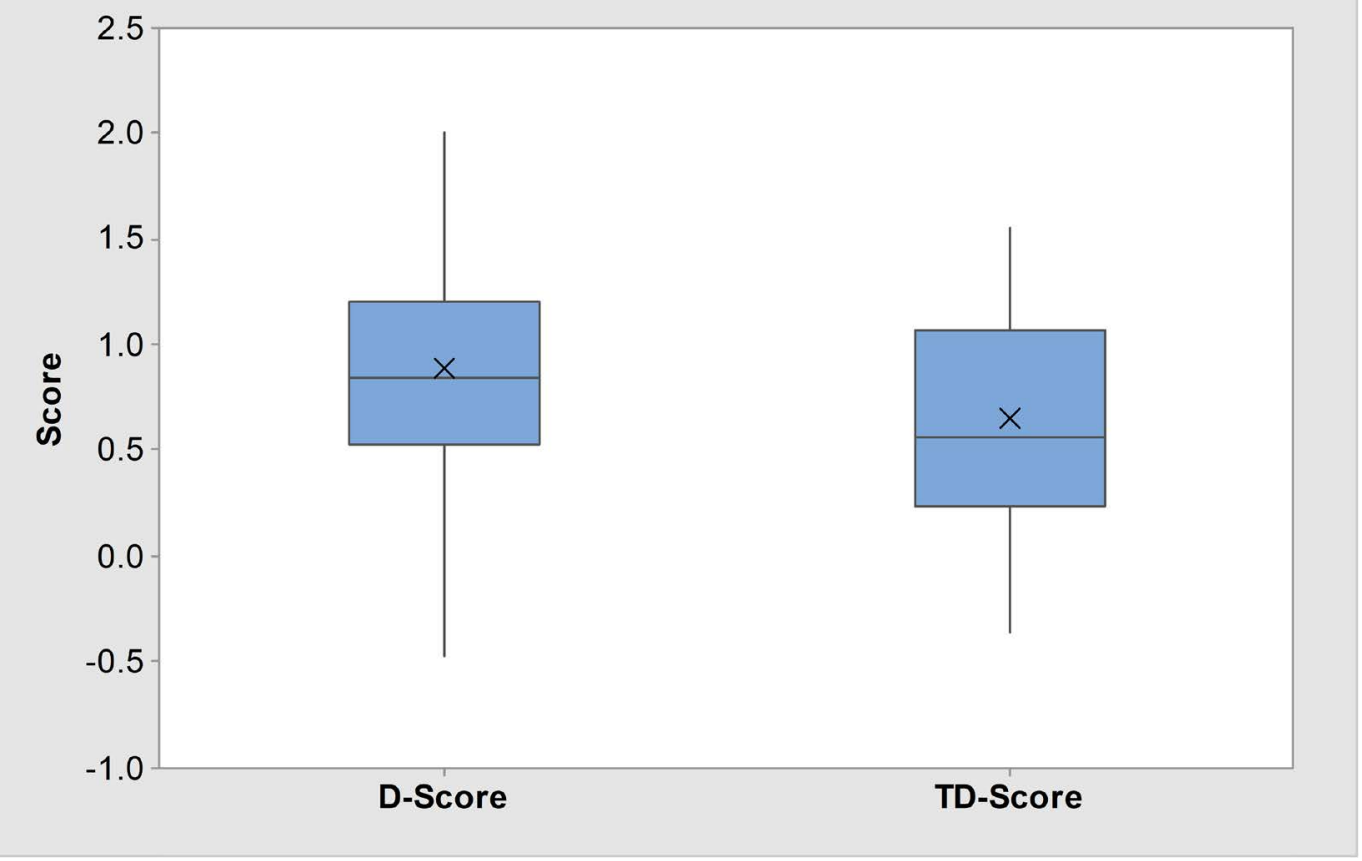

Figure 1. Distributions of D-scores (IAT) and normalised TD-scores (feeling thermometer). The median score is denoted by the centre line, the mean is the cross, the box denotes the Interquartile Range (IQR), and the upper (and lower) whiskers extend to the maximum (and minimum) data point within 1.5 times the IQR.

gave a neutral response and 7 per cent who demonstrated a preference for grey infrastructure (Figure 2). The mean implicit D-score was $0.89(\mathrm{SD}=0.52, n=41)$, indicating a slightly stronger implicit preference for BGI within the sample population (Appendix 4). D-scores ranged from -0.47 to 2.00. 90 per cent of individual responses showed an implicit preference for BGI, compared with 7 per cent who exhibited a neutral response and 2 per cent who showed an implicit preference for grey infrastructure (Figure 2). TD-scores and D-scores exhibited normal distributions (Shapiro-Wilk test, $p=0.299$ and $p=0.624$, respectively). Statistical analyses were conducted with SPSS 25.0.

A weak but statistically significant correlation was observed between TD-scores and D-scores $(r=0.380, p=0.014)$, which is comparable to correlations reported between explicit tests and IATs in earlier research (Hofmann et al. 2005, Rudman et al. 2013, O'Donnell et al. 2020a). This further demonstrates the importance of IATs in research into such environmental attitudes (Schultz et al. 2004). Despite this, TD-scores and D-scores were significantly different $(t=1.995, p=0.049$, Independent Samples T-test). Higher variability in TD-scores is demonstrated by the greater 


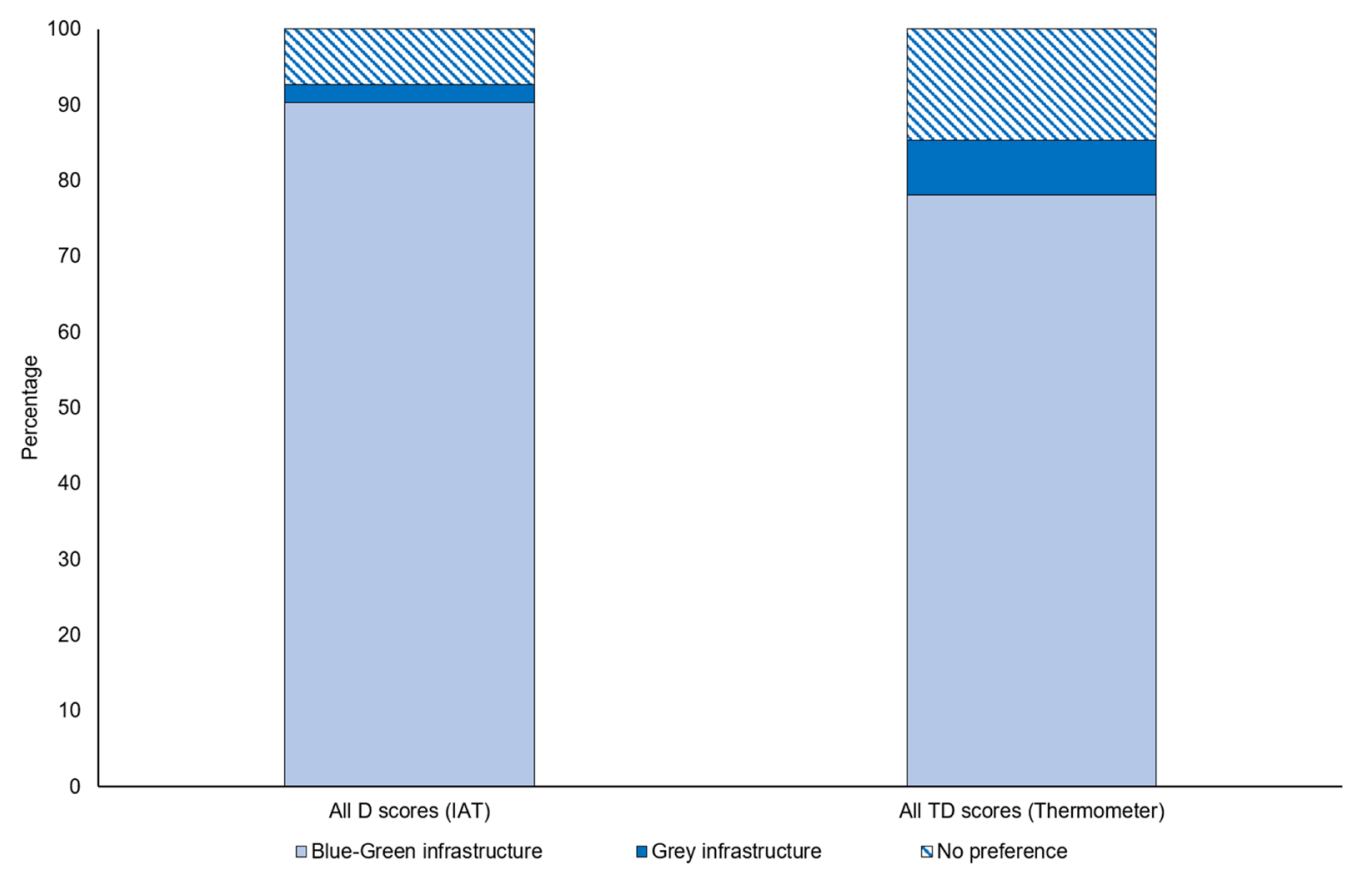

Figure 2. The percentages of respondents who demonstrated a preference for Blue-Green Infrastructure, Grey infrastructure, or no preference, for all data $(n=41)$, based on the Implicit Association Test (IAT) D-scores and Feeling Thermometer Difference (TD) scores.

interquartile range (IQR; Figure 1) compared with D-scores that clustered more around the mean with some longer whiskers (upper and lower) suggesting several strongly positive and negative individual implicit perceptions.

\section{Explicit characteristics of blue-green and grey infrastructure}

The positive average scores in the six feeling thermometer subcategories, excluding attractiveness of grey infrastructure, show that respondents have positive feelings towards blue-green and grey infrastructure (as shown in Table 3 and Figure 3) and regard both types of infrastructure as safe, tidy, useful, valuable, and necessary. However, only BGI was regarded as attractive. Overall, BGI is regarded, in a statistical sense, as significantly safer, more attractive, more useful, more valuable, and of greater necessity than grey infrastructure (Table 3, Independent Samples MannWhitney U-tests). BGI is perceived, on average, as tidier than grey infrastructure, although this relationship is not statistically significant.

Despite these overarching trends, the data reveal much variability in perceptions of blue-green and grey infrastructure. Attributes of BGI assessed by the feeling thermometers show greater agreement within the sample population (smaller standard 
Table 3. Median scores in the six feeling thermometer subcategories. All scores are normalised to a -2 to 2 scale, standard deviation is given in parentheses and the range in italics. The larger the score, the greater preference for the target variable.

\begin{tabular}{lllllll}
\hline \multirow{3}{*}{ Blue-Green } & Safety & Attractiveness & Tidiness $^{\mathrm{b}}$ & Usefulness & Valuableness & Necessity \\
& $1.60(0.66)$ & $1.56(0.60)$ & $0.80(0.74)$ & $1.80(0.54)$ & $1.72(0.49)$ & $1.84(0.61)$ \\
\multirow{3}{*}{ Grey } & -0.80 to 2.00 & -0.56 to 2.00 & -1.70 to 2.00 & -0.04 to 2.00 & -0.20 to 2.00 & -0.16 to 2.00 \\
& $1.16(0.94)$ & $-0.96(0.81)$ & $0.68(0.97)$ & $1.20(0.78)$ & $1.12(0.69)$ & $1.20(0.81)$ \\
& -2.00 to 2.00 & -2.00 to 0.72 & -1.60 to 2.00 & -1.04 to 2.00 & -0.80 to 2.00 & -1.28 to 2.00 \\
p-value $^{\mathrm{a}}$ & $\underline{0.008}$ & $\underline{0.000}$ & 0.133 & $\underline{0.003}$ & $\underline{0.000}$ & $\underline{0.016}$ \\
\hline
\end{tabular}

${ }^{a}$ Significant difference between Blue-Green and Grey scores under each category were assessed using IndependentSamples Mann-Whitney U-tests; significant differences at the $p=0.05$ level are underlined. Data in all subcategories, excluding 'Tidiness-Blue-Green' and 'Valuable - Grey exhibited non-normal distributions (Shapiro-Wilk test, $p \leq 0.05$ ).

${ }^{\mathrm{b}}$ Tidiness or maintained (US test).

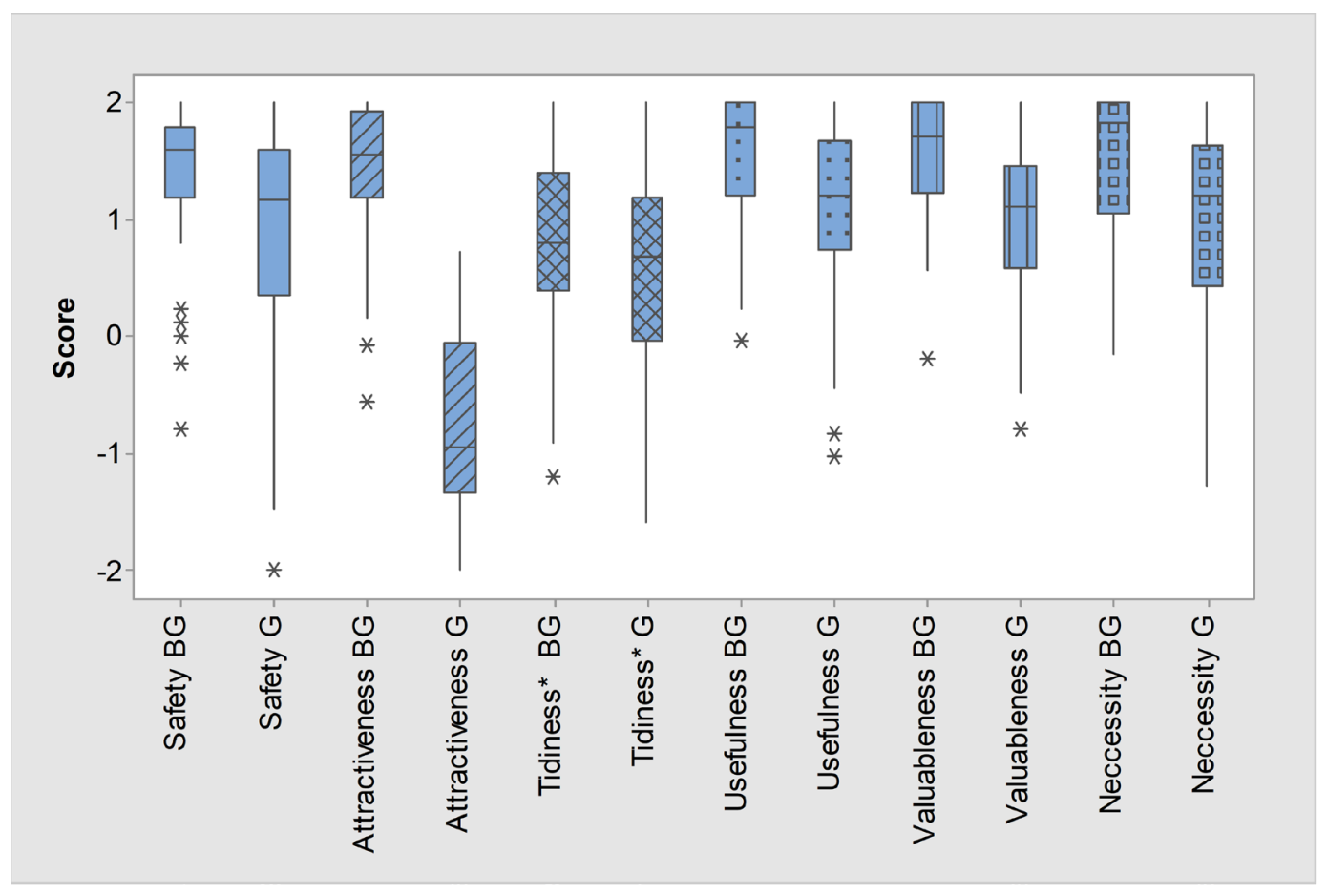

Figure 3. Distributions of feeling thermometer scores for Blue-Green (BG) and Grey (G) infrastructure in the six categories. The median score is denoted by the centre line, the box denotes the Interquartile Range (IQR), and the upper (and lower) whiskers extend to the maximum (and minimum) data point within 1.5 times the IQR. Outliers (starred) are data points beyond the lower whiskers. *tidiness or maintained (US test). 
deviations and IQRs) when compared with grey infrastructure where views are more variable (Figure 3). The longer negative whiskers for the grey infrastructure attributes suggest that several respondents feel strongly that grey infrastructure is unsafe, unattractive, untidy, useless, not valuable, and unnecessary. Aside from the unattractiveness of grey infrastructure that is supported by the majority ( 76 per cent) of respondents, negative perceptions of the other attributes of grey infrastructure typically represent a minority of strong negative preferences within the general population that regard grey infrastructure more favourably, including three respondents with outlier scores (two from Ningbo, one from Portland). With regards to BGI, several respondents hold negative perceptions of BGI attributes, as represented by the negative outliers in Figure 3 for BGI safety (5), attractiveness (2), tidiness (1), usefulness (1), and valuableness (1). The outliers for BGI attributes represent six respondents, all from Ningbo.

Significant positive correlations were observed between several BGI attributes, including attractiveness and tidiness $(r=0.429, p=0.006)$ and safety and usefulness $(r=0.460, p=0.002)$ (Spearman's rank-order correlations, detailed in Appendix 5). The strongest correlations were observed between usefulness and necessity $(r=0.657$, $p=0.000)$, usefulness and valuableness $(r=0.610, p=0.000)$, and valuableness and necessity $(r=0.816, p=0.000)$. Similarly, the usefulness and valuableness of grey infrastructure were positively correlated $(r=0.603, p=0.000)$, as were usefulness and necessity $(r=0.456, p=0.003)$, valuableness and necessity $(r=0.495, p=0.001)$, and safety and usefulness $(r=0.567, p=0.000)$.

\section{Discussion}

Using IATs to assess perceptions of blue-green and grey infrastructure held by professional stakeholders working closely with these infrastructures is a notable advance from tests solely employing explicit measures (Miller \& Montalto 2019, Shandas et al. 2019, Suppakittpaisarn et al. 2019). The data presented in this paper contribute to our growing understanding of the complexity of attitudes towards bluegreen and grey infrastructure, and attributes that influence preferences (for example, safety, attractiveness, and necessity), by presenting insight into unconscious perceptions and subsequently comparing those with stated preferences.

\section{Explicit and implicit preferences for blue-green and grey infrastructure}

The majority of respondents in the sample population associate BGI more closely with positive concepts (and/or less closely with negative concepts) than grey infrastructure, suggesting an agreement between conscious and subconscious attitudes 
that BGI is more highly valued than grey infrastructure. Several reasons may provide an explanation. The sample population is expected to be highly knowledgeable about the advantages, disadvantages, benefits, challenges, opportunities, and uncertainties associated with blue-green and grey infrastructure, owing to their current roles and disciplinary expertise in blue-green and grey infrastructure policy, planning, design, engineering, and implementation. Participants may acknowledge the greater multifunctionality of BGI: that is, that BGI delivers a wider range of social, environmental, and economic benefits compared with grey infrastructure (Hansen \& Pauleit 2014, Fenner 2017, Alves et al. 2019a, Paulin et al. 2020). Recognition of the multiple benefits of BGI beyond water treatment and flood control have also been highlighted in focus groups with thirteen professional stakeholders in Portland and Clark County, Washington (Shandas et al. 2019), and online surveys with twenty New York City practitioners that showed that groups most familiar with BGI (such as practitioners) typically assign the most value to the ecosystem services that BGI provides (Miller \& Montalto 2019).

Respondents may assume that BGI is a more effective use of space and, if designed with multifunctionality in mind, can address local challenges, including flooding, air pollution, urban heat island effects, and biodiversity loss (Connop et al. 2016). While the definitions of BGI and grey infrastructure given at the start of the explicit tests referred to their respective roles in flood and water management, additional benefits (for example, environmental enhancement, climate change adaptation, or improvements to health and well-being) were not mentioned to avoid potential response bias. The feeling thermometer instructions asked respondents to state, for example, how useful they feel BGI is; the context of 'usefulness' was not dictated, hence, the meaning was interpreted by the respondents before they gave their score.

BGI could also be perceived as a proxy for nature and greater preference for BGI could imply a higher connectedness with nature, compared with built environments, as observed by Schultz et al. (2004). Similarly, it could be that respondents prefer natural over built environments (Kaplan \& Kaplan 1989) and the terms 'Blue-Green infrastructure' and 'Grey infrastructure' conjured subconscious and/or conscious images of blue-green and grey systems at much larger spatial scales. Nonetheless, it is beyond the ability of the IAT to explain why implicit perceptions are more closely associated with positive concepts than grey infrastructure. Due to the relative nature of the IAT, it is also impossible to discern whether respondents have a positive association with BGI or a negative association with grey infrastructure (or both), which is an important limitation (Siegrist et al. 2006). Explanation of attitudes towards bluegreen and grey infrastructure are likely to be more nuanced and context specific, which preclude capture by the IAT or feeling thermometers. As one respondent from Portland noted: 
Grey is not good or bad but needed where it is needed. The difference is a designer's ability to know when and how much grey is needed with green and vice versa.

Two lines of evidence suggest a slightly stronger implicit (compared with explicit) preference for BGI within the sample population: a higher mean D-score (0.89) compared with the mean TD-score (0.66), and a greater percentage of individual respondents registering a positive score (above neutral) in the IAT compared with the explicit test ( 90 per cent implicit, 78 per cent explicit, Figure 2). This may be because some of the explicit concerns that respondents have towards BGI are not held in the subconsciousness; respondents are thus expressing more negative feelings than they instinctively feel. Alternatively (or in addition), respondents may rationalise about the advantages and disadvantages of grey infrastructure and decide to highlight positive attributes in the explicit tests; such positive associations may not be part of the internalised concept of grey infrastructure that respondents hold, leading to a stronger implicit (compared with explicit) preference for BGI.

These findings also suggest that social desirability bias, which would have increased the positive explicit scores given to BGI as part of an embedded response of 'liking' all greenspace, was not an important issue. Additionally, the design of the explicit tests, and particularly the attributes used in the feeling thermometers, allowed respondents to rationalise the advantages and disadvantages of grey infrastructure (for example, valuableness vs. attractiveness), which may have resulted in more negative and neutral views overall. Respondents may also have rationalised about the limitations of BGI, including the limited functionality when its design capacity is exceeded, which may be perceived as likely during extreme rainfall events now and in the future (Kabisch et al. 2016). This may have influenced the perceptions of usefulness and necessity of BGI approaches. The automatic or spontaneous nature of implicit attitudes, not available through introspection but revealed through the computerised reaction time IAT (Beattie and McGuire 2012), negates such deliberative behaviour (Nosek et al. 2002, Hofmann et al. 2005).

Variability in responses was evident, suggesting that some professional stakeholders within the sample population do have stronger implicit and explicit attitudes towards blue-green and/or grey infrastructure (D-scores ranged from -0.47 to 2.00 and TD-scores ranged from -0.36 to 1.55 ). This is further illustrated by the wide range of scores for the individual feeling thermometers measuring the six selected attributes of blue-green and grey infrastructure (as shown in Table 3 and Figure 3), and will be explored in the next section. 


\section{Perceptions of attractiveness, tidiness, safety usefulness, valuableness, and necessity}

Overall, there was consistency in the positive explicit perceptions of the safeness, tidiness, usefulness, valuableness, and necessity of blue-green and grey infrastructure. Unsurprisingly, respondents found BGI significantly more attractive than grey infrastructure, although 15 per cent of respondents scored grey infrastructure positively, suggesting some appreciation of the aesthetics of this approach. Aside from attractiveness, the negative scores for safety, tidiness, usefulness, valuableness, and necessity of grey infrastructure typically represent a minority of strong negative preferences within the general sample population that regard grey infrastructure more favourably. Outlier scores from three respondents demonstrate strong individual feelings that grey infrastructure is highly unsafe, useless, and not valuable. Similarly, several respondents also hold negative perceptions of BGI safety, attractiveness, tidiness, and valuableness, yet this is a small, outlying minority and should not unduly influence decision making around blue-green and grey infrastructure. However, the fact that the negative outliers for BGI attributes were recorded by six (out of a total of nine) respondents from Ningbo suggest that contextual factors may be influencing explicit perceptions. As five out of the ten negative outliers for BGI attributes refer to safety, there appears to be concerns within Ningbo respondents that BGI is not safe. This requires further investigation as, to our knowledge, there are no further investigations of professional Chinese stakeholder perceptions of the safety of BGI. Concerns around the safety of green roofs were raised by public respondents in Shandong province, China (Wang et al. 2017), but we cannot infer whether this reflects the views of Chinese stakeholders in general, or the specific Shandong public sample population.

The lower scores for BGI tidiness reflect the ongoing debate regarding a preference for 'messy' or 'tidy' nature; certain plant species used in BGI (for example, Juncus rushes) may be mistaken by some stakeholders for overgrown grasses and weeds and perceived as less aesthetically pleasing (Everett et al. 2018), whereas other stakeholders may regard 'messy' BGI as more aligned with natural environments (Tyrväinen et al. 2003) and, hence, desirable in urban contexts. The significant positive correlation between scores for attractiveness and tidiness suggests that 'tidy BGI' would be regarded as even more attractive within the sample population. This correlation was also observed in an earlier analysis of resident's perceptions of SuDS (O'Donnell et al. 2020a), showing agreement between explicit perceptions of residents and professional stakeholders regarding BGI aesthetics.

The lower scores for the safety of grey infrastructure may be due to some respondents perceiving greater consequences of grey infrastructure failure, which, historically, has seldom been designed to be 'safe-to-fail' (Dong et al. 2017) and can potentially induce catastrophic impacts (for example, floodwall collapse) 
(Debele et al. 2019). Grey infrastructure, like BGI, is designed for a range of different events: for example, urban highway drainage systems in China are designed to manage pluvial flood risk for 1:1 to 1:10 year events (Ministry of Housing and Urban-Rural Development 2016). However, unlike BGI, grey infrastructure is also used to manage coastal and fluvial flood risk associated with high magnitude events: for example, the Rotterdam dyke rings are designed for between 1:4,000 and 1:10,000 year events (City of Rotterdam 2013). While the definition of grey infrastructure that was provided at the start of the explicit test referred to 'the human-engineered infrastructure used in conventional piped drainage, storage, water treatment and water supply systems', and gave examples of 'storm drains, storage tanks, culverts, subsurface pipes and combined sewer overflows', it is possible that respondents had an entrenched concept of grey infrastructure that included larger scale assets, which subsequently influenced their responses. The design standards of BGI systems vary by scheme and by city: for example, most urban BGI in the Chinese Sponge Cities are designed to drain runoff from up to 1:30 year rainfall events (Chan et al. 2018), whereas the design standard for most UK SuDS is 1:30 years as a minimum (Woods Ballard et al. 2015). Consequentially, the risks associated with rainfall events exceeding the design standards of BGI are lower; if exceedance pathways are included, then BGI can be designed to provide some flood reduction benefit when its design capacity is exceeded (Digman et al. 2014).

Most respondents regard BGI as significantly safer, more useful, more valuable, and of greater necessity than grey infrastructure, which suggests a widespread acknowledgement of the functionality (or multifunctionality) of BGI and benefits beyond aesthetics. BGI could be perceived as more useful and valuable due to concurrent delivery of multiple environmental and social benefits in addition to the intended benefit to, typically, flood and water management, as discussed in the preceding paragraph. BGI may be perceived as of greater necessity when compared with grey infrastructure due to its ability to reduce vulnerability to other climate change risks beyond flooding, such as heat stress, water shortages, and air pollution (Demuzere et al. 2014). Both Rotterdam and Portland have developed strategies to address climate change - for example, the Rotterdam Climate Change Adaptation Strategy (City of Rotterdam 2013) and Portland's Climate Action Plan (City of Portland and Multnomah County 2016) - and, hence, the necessity of BGI to address multiple components of these strategies may have been in the consciousness of the respondents. Likewise, Policy CS16 (Climate Change) in the Core Strategy and Urban Core Plan for Gateshead and Newcastle upon Tyne 2010-2030 (UK) refers to development providing resilience to the ongoing and predicted impacts of climate change through appropriate location, design, and landscaping (Newcastle City Council and Gateshead Council 2015). Existing grey pipe systems designed to manage urban water have 
reduced the ability to modify system performance in light of future, uncertain, changes in climate and may also lead to technical lock-in (Ashley et al. 2020, Kapetas \& Fenner 2020), which may further reduce the perception of usefulness, valuableness, and necessity. In contrast, BGI is acknowledged for its greater adaptability and higher system sustainability under uncertain futures (Dong et al. 2017).

The significant positive correlations between usefulness, valuableness, and necessity of BGI and grey infrastructure could imply a similar interpretation of the meaning of the three attributes, and, hence, using all three may be redundant in future studies. In this investigation, TD-scores were calculated by subtracting the average BGI score from the average grey infrastructure score, using an average of the scores for the six attributes. Excluding valuableness and usefulness, and calculating the average BGI and grey scores based on values given for safety, attractiveness, tidiness, and necessity only, did not affect the TD-score (Appendix 6). Interestingly, if attractiveness scores are removed from the TD-score calculation, the TD-score is reduced by 50 per cent (from 0.66 to 0.33 , Appendix 6). This implies that attractiveness is a key influential factor in positive perceptions of BGI, and, if attractiveness was not assessed, the preference for blue-green compared with grey infrastructure would be weaker and approaching neutral (0.2).

\section{Integrated systems of blue-green-grey infrastructure}

Although most respondents in the sample population associate BGI more closely with positive concepts (and/or less closely with negative concepts) than grey infrastructure, the majority of individual positive explicit perceptions of the safeness, tidiness, usefulness, valuableness, and necessity of blue-green and grey infrastructure suggest that both infrastructure types are valued by the sample population, albeit, with regards to grey infrastructure, on an explicit level only. From this we can infer that integrated systems of blue-green and grey infrastructure may be a preferable strategy in managing urban water and mitigating the impacts of climate change, in addition to delivering benefits to the environment, society, and economy. There is a growing body of evidence that resilience against future environmental threats cannot be achieved by traditional grey infrastructure systems alone, and combinations of blue-green and grey infrastructure can enhance system performance and maximise climate adaptation in cities (Dong et al. 2017, Alves et al. 2019b, Browder et al. 2019, Debele et al. 2019, Frantzeskaki et al. 2019, O'Donnell et al. 2020b, Kapetas \& Fenner 2020). The use of traditional buried pipe networks to address, for example, future water challenges associated with climate change and increased urbanisation, is likely to be unaffordable, miss wider opportunities that integrated blue-green and grey approaches could deliver (Dolman \& Ogunyoye 2018, Ashley et al. 2020), and potentially lead to overdesigned 
solutions or inadequate system extensions that fail to provide the required additional capacity (O'Donnell \& Thorne 2020). BGI and Nature-Based Solutions (NBS) are typically more cost effective than hard engineering approaches used within existing systems, particularly when wider co-benefits are quantified and, where possible, monetised (Braden \& Ando 2011, Ando \& Netusil 2018, Debele et al. 2019).

Taking the projected increase in frequency and intensity of rainfall events as an example (IPCC 2014), the potential integration of blue-green and grey infrastructure to manage urban rainfall can be viewed through four domains, with different combinations of blue-green-grey assets needed to deliver maximum benefit in urban areas: 1) urban resource (everyday rainfall); 2) urban drainage (design rainfall); 3) exceedance design (exceedance rainfall); and 4) flooding domain (extreme rainfall) (Fratini et al. 2012, Ashley et al. 2020). Combined systems of blue-green-grey infrastructure can manage pluvial flood risk in all domains. In Domain 1, BGI should play a key role in managing smaller rainfall events, which are within the design standard of most assets, and is typically included at an urban planning stage to manage low levels of risk while contributing to quality of place. At the other end of the scale (Domain 4), the impacts of extreme rainfall events can be minimised through effective emergency response measures (including evacuation) and provision of floodable areas. This could include BGI assets such as playing fields, parks ,and open greenspace, in addition to grey infrastructure assets specifically designed to reduce pluvial flood risk, such as the Benthemplein water square in Rotterdam, which manages rainwater while redeveloping the urban environment (Hölscher et al. 2019), or designated as floodable, such as car parks. The optimum mix is highly dependent on local conditions (Dong et al. 2017, Kapetas \& Fenner 2020).

An integrated blue-green-grey approach increases the complexity of options and delivery, moving from a mono-solution problem when grey infrastructure is the sole consideration (Ashley et al. 2020) to a multifaced challenge involving a range of public and private stakeholders from different disciplinary standpoints, and consideration of multiple co-benefits beyond water and flood risk management. Nonetheless, integrated blue-green-grey approaches are recommended to help cities progress towards the Sustainable Development Goals (SDGs), particularly around good health and wellbeing (SDG3), clean water and sanitation (SDG6), and sustainable cities and communities (SDG11). An adaptation pathways approach can reduce this complexity and allow incremental investment in infrastructure to meet future performance requirements while maintaining cost-effectiveness and multiple benefit provision (Kapetas \& Fenner 2020). Using a residential case study in a London Borough, Kapetas and Fenner (2020) show that combining BGI interventions (storage pond, bioretention cells, and permeable paving) with the existing grey infrastructure system can more effectively manage future flood risk and maximise other co-benefits 
(for example, amenity, carbon sequestration, and groundwater recharge opportunities), when compared with grey infrastructure expansion alone. Determining the importance of each benefit at the start of spatial development strategy planning is recommended; not all benefits can be optimised simultaneously and trade-offs will need to be made regarding which risks are to be minimised (Caparros-Midwood et al. 2019). For instance, if a blue-green-grey strategy driven by flood risk management objectives achieves the highest total benefit, but compromises flood damage reduction, such a trade-off may not be acceptable to the stakeholders involved (Alves et al. 2019b). Smart Specialisation Strategy, to achieve the objectives of cohesion policy, may be drawn upon to enable regional authorities to identify technological domains to concentrate investment and innovation (D'Adda et al. 2020), in this case focusing on innovative systems of integrated blue-green-grey infrastructure.

\section{Limitations and directions for future research}

The IAT is widely used to reveal implicit attitudes through the strength of conceptattribute associations. Limitations of this method, including the inability to discern whether respondents have a positive association with one target-concept and/or a negative association with the other, were discussed in earlier literature (e.g., Greenwald et al. 1998, Rudman et al. 1999, Siegrist et al. 2006, Gregg \& Klymowsky 2013). The logistical challenges, namely the need for a computer to complete the test, are less relevant in current society, and particularly in the professional stakeholder sampling frame used in this study. Still, variations in internet speeds, computer specifications, and distractions may have affected the response times when respondents completed the online IAT, influencing the resultant implicit score. The software is designed to minimise this potential issue: for example, by training respondents first in the two trial runs before the initial combined task (Table 2) and by eliminating responses that exceeded 10,000 ms. Nonetheless, it is accepted that the degree of variability and noise may be larger with implicit attitude measures, when compared with explicit measures (Schultz et al. 2004).

Designing the feeling thermometers without a default value is expected to have limited any bias associated with the slider starting position (Liu \& Conrad 2019), and thus recorded a representative indication of how the respondents feel towards the six attributes tested. The explicit test score (Thermometer Difference or TD-score), however, is dependent on the attributes used in the feeling thermometers, and it is possible that using different words would have resulted in different scores. This could have resulted in greater explicit preference for BGI (compared with implicit), or even an explicit preference for grey infrastructure. TD-scores calculated using values given for safety, attractiveness, tidiness, and necessity (so excluding valuableness and usefulness) 
did not affect the TD-score, but removing attractiveness from the TD-score calculation reduced the TD-score by 50 per cent (Appendix 6). The selection of attributes in the explicit tests, and the degree to which the explicit measure is directly or indirectly related to the representation assessed in the IAT, are of paramount importance and influence the degree to which explicit and implicit scores can be compared (Hofmann et al. 2005).

The IATs and feeling thermometer tests are unable to explain why certain attitudes and preferences are held within the sample population. Future research could build on this study by explicitly asking respondents why they perceive (or do not perceive) blue-green and grey infrastructure as attractive, safe, tidy or well-maintained, useful, valuable, and necessary, and exploring their feelings towards integrated systems of blue-green-grey infrastructure to address climate change adaptation objectives. Further research could explore more applied questions: for example, investigating whether experience of flood events influences implicit perceptions of blue-green and grey infrastructure, as direct experience with extreme weather events is acknowledged as an effective catalyst for changing implicit attitudes (Rudman et al. 2013). Collecting data from a larger sample population in each of the four cities, which would have permitted a comparison of perceptions in Newcastle, Ningbo, Portland, and Rotterdam, and an investigation into whether location and associated governance characteristics could influence implicit perceptions of BGI, may not be possible due to the limited population (in each city) of professional stakeholders working with BGI. However, this should be investigated in future research. Additionally, evaluating whether broader environmental attitudes around climate change influence perceptions of blue-green and grey infrastructure could also develop insight into why certain perceptions are held.

\section{Conclusion}

Blue-Green Infrastructure (BGI) is increasingly acknowledged as a strategy to reduce the impacts of climate change in urban environments and reduce vulnerability to risks such as flooding, heat stress, and water shortages, while delivering a range of additional co-benefits to the environment and society. Through the development of a novel application of the Implicit Association Test (IAT), this study investigated the perceptions of BGI held by professional stakeholders in four cities with leading BGI programmes and aspirations (Newcastle, UK; Rotterdam, Netherlands; Portland, Oregon USA; and Ningbo, China). This is the first time an IAT about BGI has focused on professional stakeholders, and the first comparative study of the implicit and explicit perceptions that professional stakeholders have of blue-green and grey infrastructure, 
and, hence, presents a novel exploration of whether stated preferences for BGI align with unconscious perceptions. It is also the first study to explore professional stakeholders' explicit perceptions of the attractiveness, tidiness, safety usefulness, valuableness, and necessity of blue-green and grey infrastructure. The IAT contributes additional insight into underlying attitudes that are more entrenched in respondents' value systems and cannot be captured by explicit tests, by removing many of the external influences and self-presentation effects (for example, social desirability bias) that affect explicit tests. Implicit attitudes have been little studied in the flood and water management discipline, yet may play a key role in influencing overarching attitudes towards BGI, and improving our understanding of potential disconnects between positive attitudes towards blue-green spaces and behaviours around them (O’Donnell et al. 2020a).

Blue-green and grey infrastructure are perceived positively by the sample population, suggesting that they are valued components of landscapes, albeit for different reasons. Stated preferences therefore align with automatic preferences assessed by the IAT. Overall, respondents implicitly and explicitly prefer BGI, and regard it as safer, tidier, more attractive, useful, valuable, and necessary. This suggests a widespread acknowledgement of the functionality (or multifunctionality) of BGI and benefits beyond aesthetic value. As an example, BGI may be regarded as of greater necessity when compared with grey infrastructure due to its ability to reduce vulnerability to other climate change risks beyond flooding, such as heat stress and water shortages. We can infer by the positive perceptions of BGI expressed by the professional stakeholders in this study that their personal perceptions are not barriers to implementation of BGI in their respective cities, as previously assumed (O'Donnell et al. 2017, Shandas et al. 2019), and other technical and socio-political factors are slowing down BGI progress. However, concerns over the safety of BGI expressed by 50 per cent of the Ningbo respondents may be a barrier to future implementation of bluegreen systems. The individual positive explicit perceptions of grey infrastructure, nonetheless, suggest that integrated blue-green and grey systems may be preferable for professional stakeholders to incorporate into urban water management and climate change adaptation strategies. This is based on inferred experts' perceptions that resilience against future environmental threats cannot be achieved by traditional grey infrastructure systems alone, and that combinations of blue-green and grey infrastructure can improve system performance, increase urban climate adaptation, and further enhance urban environments and quality of life for citizens. Exploring implicit perceptions of integrated systems of blue-green-grey infrastructure designed to address climate change adaptation objectives is an important direction for future research. 


\section{Acknowledgements}

This research was performed as part of the British Academy project 'Developing new Blue-Green futures: multifunctional infrastructure to address water challenges', part of the British Academy programme on Tackling the UK's International Challenges (IC3\100093). We are extremely grateful to Dr Anush Poghosyan for developing the four online Implicit Association Tests (IAT), in three different languages, and for assistance with data retrieval. We would also like to express our thanks to Miss Lei Li (University of Nottingham Ningbo China) for her support collecting data in China, and to all respondents who gave their time to complete the survey.

\section{References}

Alves, A., Gersonius, B., Kapelan, Z., Vojinovic, Z. \& Sanchez, A. (2019a), 'Assessing the Co-benefits of Green-blue-Grey Infrastructure for Sustainable Urban Flood Risk Management', Journal of Environmental Management, 239: 244-54. https://doi.org/10.1016/j.jenvman.2019.03.036

Alves, A., Vojinovic, Z., Kapelan, Z., Sanchez, A. \& Gersonius, B. (2019b), 'Exploring Trade-offs Among the Multiple Benefits of Green-blue-Grey Infrastructure for Urban Flood Mitigation', Science of The Total Environment: 134980. https://doi.org/10.1016/j.scitotenv.2019.134980

Amec Foster Wheeler (2016), 'Newcastle City Strategic Surface Water Management Plan. Final Report', Report No 36634/F/001. https://www.newcastle.gov.uk/sites/default/files/2019-01/ newcastle_city_strategic_surface_water_management_plan_jan_2016.pdf

Ando, A.W. \& Netusil, N.R. (2018), 'Valuing the Benefits of Green Stormwater Infrastructure', in Oxford Research Encyclopedia of Environmental Science (Oxford, Oxford University Press). https://doi.org/10.1093/acrefore/9780199389414.013.605

Arnell, N.W., Brown, S., Gosling, S.N., Hinkel, J., Huntingford, C., Lloyd-Hughes, B., Lowe, J.A., Osborn, T., Nicholls, R. \& Zelazowski, P. (2016), 'Global-scale Climate Impact Functions: The Relationship Between Climate Forcing and Impact', Climatic Change, 134: 475-87. https://doi.org/10.1007/s10584-013-1034-7

Ashley, R., Gersonius, B. \& Horton, B. (2020), 'Managing Flooding: From a Problem to an Opportunity', Philosophical Transactions of the Royal Society A, 378(2168): 20190214. https://doi.org/10.1098/rsta.2019.0214

Aylett, A. (2015), 'Institutionalizing the Urban Governance of Climate Change Adaptation: Results of an International Survey', Urban Climate, 14: 4-16. https://doi.org/10.1016/j.uclim.2015.06.005

Baumeister, R.F. \& Hutton, D.G. (1987), 'Self-presentation Theory: Self-construction and Audience Pleasing', in B. Mullen \& G.R. Goethals (eds) Theories of Group Behavior (Cham, Springer), 71-87. https://doi.org/10.1007/978-1-4612-4634-3_4

Beattie, G. \& McGuire, L. (2012), 'See No Evil? Only Implicit Attitudes Predict Unconscious Eye Movements Towards Images of Climate Change', Semiotica, 192: 315-39. https://doi.org/10.1515/sem-2012-0066

Blue-Green Futures (2019), Blue-Green Futures blog. https://blogs.nottingham.ac.uk/bluegreenfutures/ [accessed 24 April 2020].

Braden, J.B. \& Ando, A.W. (2011), 'Economic Costs, Benefits, and Achievability of Low-impact Development-based Stormwater Regulations', in H.W. Thurston (ed.) Economic Incentives for Stormwater Control (Boca Raton, FL, CRC Press), 45-70. https://doi.org/10.1201/b11071-4 
Browder, G., Ozment, S., Rehberger Bescos, I., Gartner, T. \& Lange, G.-M. (2019), Integrating Green and Gray: Creating Next Generation Infrastructure (Washington, DC, World Bank and World Resources Institute). https://openknowledge.worldbank.org/handle/10986/31430 [accessed 20 May 2020]. https://doi.org/10.46830/wrirpt.18.00028

Brown, R. \& Farrelly, M. (2009), 'Delivering Sustainable Urban Water Management: A Review of the Hurdles We Face', Water Science and Technology, 59(5): 839-46. https://doi.org/10.2166/wst.2009.028

Bruni, C.M. \& Schultz, P.W. (2010), 'Implicit Beliefs About Self and Nature: Evidence from an IAT Game', Journal of Environmental Psychology, 30(1): 95-102. https://doi.org/10.1016/j.jenvp.2009.10.004

Caparros-Midwood, D., Dawson, R. \& Barr, S. (2019), 'Low Carbon, Low Risk, Low Density: Resolving Choices About Sustainable Development in Cities', Cities, 89: 252-67. https://doi.org/10.1016/j.cities.2019.02.018

Carter, J.G., Handley, J., Butlin, T. \& Gill, S. (2018), 'Adapting Cities to Climate Change-Exploring The Flood Risk Management Role of Green Infrastructure Landscapes', Journal of Environmental Planning and Management, 61(9): 1535-52. https://doi.org/10.1080/09640568.2017.1355777

Chan, F.K.S., Griffiths, J.A., Higgitt, D., Xu, S., Zhu, F., Tang, Y-T., Xu, Y. \& Thorne, C (2018), "Sponge City" in China-A Breakthrough of Planning and Flood Risk Management in the Urban Context', Land Use Policy, 76: 772-8. https://doi.org/10.1016/j.landusepol.2018.03.005

City of Melbourne (2017) Climate Change Adaptation Strategy Refresh. https://www.melbourne.vic.gov. au/sitecollectiondocuments/climate-change-adaptation-strategy-refresh-2017.pdf [accessed 8 May 2020].

City of Portland and Multnomah County (2016) Climate Action Plan. https://www.portlandoregon. gov/bps/article/531984 [accessed 5 February 2019].

City of Rotterdam (2013) Rotterdam Climate Change Adaptation Strategy. http://www.deltacityofthefuture.nl/documents/20121210_RAS_EN_lr_versie_4.pdf [accessed 27 July 2020].

Connop, S., Vandergert, P., Eisenberg, B., Collier, M.J., Nash, C., Clough, J. \& Newport, D. (2016), 'Renaturing Cities Using a Regionally-focused Biodiversity-led Multifunctional Benefits Approach to Urban Green Infrastructure', Environmental Science \& Policy, 62: 99-111. https://doi.org/10.1016/j.envsci.2016.01.013

D’Adda, D., Iacobucci, D. \& Palloni, R. (2020), 'Relatedness in the Implementation of Smart Specialisation Strategy: A First Empirical Assessment', Papers in Regional Science, 99: 405-25. https://doi.org/10.1111/pirs.12492

Dawson, R.J., Thompson, D., Johns, D., Wood, R., Darch, G., Chapman, L., Hughes, P.N., Watson, G.V., Paulson, K., Bell, S., Gosling, S.N., Powrie, W. \& Hall, J.W. (2018), 'A Systems Framework for National Assessment of Climate Risks to Infrastructure', Philosophical Transactions of the Royal Society A, 376: 20170298. https://doi.org/10.1098/rsta.2017.0298

Debele, S.E., Kumar, P., Sahani, J., Marti-Cardona, B., Mickovski, S.B., Leo, L.S., Porcù, F., Bertini, F., Montesi, D., Vojinovic, Z. \& Di Sabatino, S. (2019), 'Nature-based Solutions for Hydrometeorological Hazards: Revised Concepts, Classification Schemes and Databases', Environmental Research, 179(B): 108799. https://doi.org/10.1016/j.envres.2019.108799

De Houwer, J. (2001), 'A Structural and Process Analysis of the Implicit Association Test', Journal of Experimental Social Psychology, 37(6): 443-51. https://doi.org/10.1006/jesp.2000.1464

Demuzere, M., Orru, K., Heidrich, O., Olazabal, E., Geneletti, D., Orru, H., Bhave, A.G., Mittal, N., Feliu, E. \& Faehnle, M. (2014), 'Mitigating and Adapting to Climate Change: Multi-functional and Multi-scale Assessment of Green Urban Infrastructure', Journal of Environmental Management, 146: 107-15. https://doi.org/10.1016/j.jenvman.2014.07.025 
Derkzen, M.L., van Teeffelen, A.J. \& Verburg, P.H. (2017), 'Green Infrastructure for Urban Climate Adaptation: How Do Residents' Views on Climate Impacts and Green Infrastructure Shape Adaptation Preferences?' Landscape and Urban Planning, 157: 106-30. https://doi.org/10.1016/j.landurbplan.2016.05.027

Digman, C., Ashley, R., Hargreaves, P. \& Gill, E. (2014), 'Managing Urban Flooding from Heavy Rainfall-Encouraging the Uptake of Designing for Exceedance', report C738, CIRIA, London.

Dolman, N. \& Ogunyoye, F. (2018), 'How Water Challenges Can Shape Tomorrow's Cities', Proceedings of the Institution of Civil Engineers-Civil Engineering, 171: 2-30. https://doi.org/10.1680/jcien.17.00052

Dong, X., Guo, H. \& Zeng, S. (2017), 'Enhancing Future Resilience in Urban Drainage System: Green Versus Grey Infrastructure', Water Research, 124: 280-9. https://doi.org/10.1016/j.watres.2017.07.038

European Commission (2020), Smart Specialisation Platform. https://s3platform.jrc.ec.europa.eu/what-is-smart-specialisation [accessed 25 March 2021].

Everett, G., Morzillo, A., Lamond, J., Matsler, M. \& Chan, F. (2018), 'Delivering Green Streets: An Exploration of Changing Perceptions and Behaviours Over Time Around Bioswales in Portland, Oregon', Journal of Flood Risk Management, 11(S2): S973-S985.

https://doi.org/10.1111/jfr3.12225

Fenner, R. (2017), 'Spatial Evaluation of Multiple Benefits to Encourage Multi-functional Design of Sustainable Drainage in Blue-green Cities', Water, 9(12): 953. https://doi.org/10.3390/w9120953

Frantzeskaki, N., McPhearson, T., Collier, M.J., Kendal, D., Bulkeley, H., Dumitru, A., Walsh, C., Noble, K., Van Wyk, E. \& Ordóñez, C. (2019), 'Nature-based Solutions for Urban Climate Change Adaptation: Linking Science, Policy, and Practice Communities for Evidence-based Decision-making', BioScience, 69(6): 455-66. https://doi.org/10.1093/biosci/biz042

Fratini, C., Geldof, G.D., Kluck, J. \& Mikkelsen, P.S. (2012), 'Three Points Approach (3PA) for Urban Flood Risk Management: A Tool to Support Climate Change Adaptation Through Transdisciplinarity and Multifunctionality', Urban Water Journal, 9(5): 317-31. https://doi.org/10.1080/1573062X.2012.668913

Gill, S.E., Handley, J.F., Ennos, A.R. \& Pauleit, S. (2007), 'Adapting Cities for Climate Change: The Role of the Green Infrastructure', Built Environment, 33(1): 115-33. https://doi.org/10.2148/benv.33.1.115

Greenwald, A.G. \& Banaji, M.R. (1995), 'Implicit Social Cognition: Attitudes, Self-esteem, and Stereotypes', Psychological Review, 102(1): 4-27. https://doi.org/10.1037/0033-295X.102.1.4

Greenwald, A.G., McGhee, D.E. \& Schwartz, J.L. (1998), 'Measuring Individual Differences in Implicit Cognition: The Implicit Association Test', Journal of Personality and Social Psychology, 74(6): 1464-80. https://doi.org/10.1037/0022-3514.74.6.1464

Greenwald, A.G., Nosek, B.A. \& Banaji, M.R. (2003), 'Understanding and Using the Implicit Association Test: I. An Improved Scoring Algorithm', Journal of Personality and Social Psychology, 85(2): 197-216. https://doi.org/10.1037/0022-3514.85.2.197

Gregg, A.P. \& Klymowsky, J. (2013), 'The Implicit Association Test in Market Research: Potentials and Pitfalls', Psychology \& Marketing, 30(7): 588-601. https://doi.org/10.1002/mar.20630

Gudmundsson, L., Boulange, J., Do, H.X., Gosling, S.N., Grillakis, M.G., Koutroulis, A.G., Leonard, M., Liu, J., Schmied, H.M. \& Papadimitriou, L. (2021), 'Globally Observed Trends in Mean and Extreme River Flow Attributed to Climate Change', Science, 371: 1159-62. https://doi.org/10.1126/science.aba3996

Guerreiro, S.B., Dawson, R.J., Kilsby, C., Lewis, E. \& Ford, A. (2018), 'Future Heat-waves, Droughts and Floods in 571 European Cities', Environmental Research Letters, 13(3): 034009. https://doi.org/10.1088/1748-9326/aaaad3 
Hansen, R. \& Pauleit, S. (2014), 'From Multifunctionality to Multiple Ecosystem Services? A Conceptual Framework for Multifunctionality in Green Infrastructure Planning for Urban Areas', Ambio, 43(4): 516-29. https://doi.org/10.1007/s13280-014-0510-2

Hayden, L., Cadenasso, M.L., Haver, D. \& Oki, L.R. (2015), 'Residential Landscape Aesthetics and Water Conservation Best Management Practices: Homeowner Perceptions and Preferences', Landscape and Urban Planning, 144: 1-9. https://doi.org/10.1016/j.landurbplan.2015.08.003

Hofmann, W., Gawronski, B., Gschwendner, T., Le, H. \& Schmitt, M. (2005), 'A Meta-analysis on the Correlation Between the Implicit Association Test and Explicit Self-report Measures', Personality and Social Psychology Bulletin, 31(10): 1369-85. https://doi.org/10.1177/0146167205275613

Hölscher, K., Frantzeskaki, N., McPhearson, T. \& Loorbach, D. (2019), 'Tales of Transforming Cities: Transformative Climate Governance Capacities in New York City, US and Rotterdam, Netherlands', Journal of Environmental Management, 231: 843-57. https://doi.org/10.1016/j.jenvman.2018.10.043

IPCC (2014), 'Climate Change 2014: Impacts, Adaptation, and Vulnerability. Part B: Regional Aspects', in V.R. Barros, C.B. Field, D.J. Dokken, M.D. Mastrandrea, K.J. Mach, \& T.E. Bilir (eds) Contribution of Working Group II to the Fifth Assessment Report of the Intergovernmental Panel on Climate Change (Cambridge, Cambridge University Press).

Jiang, Y., Zevenbergen, C. \& Fu, D. (2017), 'Understanding the Challenges for the Governance of China's "Sponge Cities" Initiative to Sustainably Manage Urban Stormwater and Flooding', Natural Hazards, 89(1): 521-9. https://doi.org/10.1007/s11069-017-2977-1

Kabisch, N., Frantzeskaki, N., Pauleit, S., Naumann, S., Davis, M., Artmann, M., Haase, D., Knapp, S., Korn, H. \& Stadler, J. (2016), 'Nature-based Solutions to Climate Change Mitigation and Adaptation in Urban Areas: Perspectives on Indicators, Knowledge Gaps, Barriers, and Opportunities for Action', Ecology and Society, 21(2): 39. https://doi.org/10.5751/ES-08373-210239

Kapetas, L. \& Fenner, R. (2020), 'Integrating Blue-green and Grey Infrastructure Through an Adaptation Pathways Approach to Surface Water Flooding', Philosophical Transactions of the Royal Society A, 378: 20190204. https://doi.org/10.1098/rsta.2019.0204

Kaplan, R. \& Kaplan, S. (1989), The Experience of Nature: A Psychological Perspective (Cambridge, Cambridge University Press).

Lamond, J. \& Everett, G. (2019), 'Sustainable Blue-Green Infrastructure: A Social Practice Approach to Understanding Community Preferences and Stewardship', Landscape and Urban Planning, 191: 103639. https://doi.org/10.1016/j.landurbplan.2019.103639

Liu, M. \& Conrad, F.G. (2019), 'Where Should I Start? On Default Values for Slider Questions in Web Surveys', Social Science Computer Review, 37(2): 248-69. https://doi.org/10.1177/0894439318755336

Liu, T., Geng L., Ye, L. \& Zhou, K. (2019), “"Mother Nature” Enhances Connectedness to Nature and Pro-environmental Behavior', Journal of Environmental Psychology, 61: 37-45. https://doi.org/10.1016/j.jenvp.2018.12.003

McPhillips, L.E. \& Matsler, A.M. (2018), 'Temporal Evolution of Green Stormwater Infrastructure Strategies in Three US Cities', Frontiers in Built Environment, 4(26): 1-14. https://doi.org/10.3389/fbuil.2018.00026

Meade, A.W. (2009), 'FreeIAT: An Open-source Program to Administer the Implicit Association Test', Applied Psychological Measurement, 33(8): 643. https://doi.org/10.1177/0146621608327803

Miller, S.M. \& Montalto, F.A. (2019), 'Stakeholder Perceptions of the Ecosystem Services Provided by Green Infrastructure in New York City', Ecosystem Services, 37: 100928. https://doi.org/10.1016/j.ecoser.2019.100928 
Ministry of Housing and Urban-Rural Development (2016), Code for Design of Urban Road Engineering (CJJ37-2012), Beijing.

Newcastle City Council and Gateshead Council (2015), Planning for the Future-Core Strategy and Urban Core Plan for Gateshead and Newcastle upon Tyne 2010-2030. https://www.newcastle.gov. uk/sites/default/files/2019-01/planning_for_the_future_core_strategy_and_urban_core_ plan_2010-2030.pdf [accessed 11 May 2020].

Nosek, B.A., Banaji, M.R. \& Greenwald, A.G. (2002), 'Math= male, me= female, therefore math $\neq$ me', Journal of Personality and Social Psychology, 83(1): 44-59. https://doi.org/10.1037/0022-3514.83.1.44

Novotny, V., Ahern, J. \& Brown, P. (2010), Water Centric Sustainable Communities: Planning, Retrofitting and Building the Next Urban Environment (Hoboken, NJ, John Wiley). https://doi.org/10.1002/9780470949962

O’Donnell, E., Lamond, J. \& Thorne, C. (2017), 'Recognising Barriers to Implementation of Bluegreen Infrastructure: A Newcastle Case Study', Urban Water Journal, 14(9): 964-71. https://doi.org/10.1080/1573062X.2017.1279190

O’Donnell, E., Maskrey, S., Everett, G. \& Lamond, J. (2020a), 'Developing the Implicit Association Test to Uncover Hidden Preferences for Sustainable Drainage Systems', Philosophical Transactions of the Royal Society A, 378: 20190207. https://doi.org/10.1098/rsta.2019.0207

O’Donnell, E.C., Netusil, N.R., Chan, F.K.S., Dolman, N.J. \& Gosling, S.N. (2021), 'International Perceptions of Urban Blue-Green Infrastructure: A Comparison across Four Cities', Water, 13: 544. https://doi.org/10.3390/w13040544

O’Donnell, E., Thorne, C., Ahilan, S., Birkinshaw, S., Butler, D., Dawson, D., Everett, G., Fenner, R., Glenis, V., Kapetas, L., Kilsby, C., Krivtsov, V., Lamond, J., Maskrey, S., O’Donnell, G., Potter, K., Vercruysse, K., Vilcan, T. \& Wright, N. (2020b), 'The Blue-green Path to Urban Flood Resilience', Blue-Green Systems, 2(1): 28-45. https://doi.org/10.2166/bgs.2019.199

Özerol, G., Dolman, N., Bormann, H., Bressers, H., Lulofs, K. \& Böge, M. (2020), 'Urban Water Management and Climate Change Adaptation: A Self-assessment Study by Seven Midsize Cities in the North Sea Region', Sustainable Cities and Society, 55: 102066. https://doi.org/10.1016/j.scs.2020.102066

Paulin, M., Remme, R., de Nijs, T., Rutgers, M., Koopman, K.R., de Knegt, B., van der Hoek, D.C.J. \& Breure, A.M. (2020), 'Application of the Natural Capital Model to Assess Changes in Ecosystem Services from Changes in Green Infrastructure in Amsterdam', Ecosystem Services, 43: 101114. https://doi.org/10.1016/j.ecoser.2020.101114

Roster, C.A., Lucianetti, L. \& Albaum, G. (2015), 'Exploring Slider vs. Categorical Response Formats in Web-based Surveys', Journal of Research Practice, 11(1): 1-19.

Rudman, L.A., Greenwald, A.G., Mellott, D.S. \& Schwartz, J.L.K. (1999), 'Measuring the Automatic Components of Prejudice: Flexibility and Generality of the Implicit Association Test', Social Cognition, 17(4): 437-65. .https://doi.org/10.1521/soco.1999.17.4.437

Rudman, L.A., McLean, M.C. \& Bunzl, M. (2013), 'When Truth Is Personally Inconvenient, Attitudes Change the Impact of Extreme Weather on Implicit Support for Green Politicians and Explicit Climate-change Beliefs', Psychological Science, 21(22): 2290-6. https://doi.org/10.1177/0956797613492775

Schultz, P.W., Shriver, C., Tabanico, J.J. \& Khazian, A.M. (2004), 'Implicit Connections with Nature', Journal of Environmental Psychology, 24(1): 31-42. https://doi.org/10.1016/S0272-4944(03)00022-7

Scottish Government (2019), Climate Ready Scotland: Second Scottish Climate Change Adaptation Programme 2019-2024. https://www.gov.scot/publications/climate-ready-scotland-secondscottish-climate-change-adaptation-programme-2019-2024/ [accessed 8 May 2020]. 
Shandas, V., Matsler, A., Caughman, L. \& Harris, A. (2019), 'Towards the Implementation of Green Stormwater Infrastructure: Perspectives from Municipal Managers in the Pacific Northwest', Journal of Environmental Planning and Management, 63(6): 959-80. https://doi.org/10.1080/09640568.2019.1620708

Siegrist, M., Keller, C. \& Cousin, M.E. (2006), 'Implicit Attitudes Toward Nuclear Power and Mobile Phone Base Stations: Support for the Affect Heuristic', Risk Analysis, 26(4): 1021-9. https://doi.org/10.1111/j.1539-6924.2006.00797.x

Spence, A. \& Townsend, E. (2006), 'Implicit Attitudes Towards Genetically Modified (GM) Foods: A Comparison of Context-free and Context-dependent Evaluations', Appetite, 46(1): 67-74. https://doi.org/10.1016/j.appet.2005.09.003

Suppakittpaisarn, P., Larsen, L. \& Sullivan, W.C. (2019), 'Preferences for Green Infrastructure and Green Stormwater Infrastructure in Urban Landscapes: Differences Between Designers and Laypeople', Urban Forestry \& Urban Greening, 43: 126378. https://doi.org/10.1016/j.ufug.2019.126378

Tillie, N. \& van der Heijden, R. (2016), 'Advancing Urban Ecosystem Governance in Rotterdam: From Experimenting and Evidence Gathering to New Ways for Integrated Planning', Environmental Science \& Policy, 62: 139-44. https://doi.org/10.1016/j.envsci.2016.04.016

Tongco, M.D.C. (2007), 'Purposive Sampling as a Tool for Informant Selection', Ethnobotany Research and Applications, 5, 147-58. https://doi.org/10.17348/era.5.0.147-158

Truelove, H.B., Greenberg, M.R. \& Powers, C.W. (2014), 'Are Implicit Associations with Nuclear Energy Related to Policy Support? Evidence from the Brief Implicit Association Test', Environment and Behavior, 46(7): 898-923. https://doi.org/10.1177/0013916513480861

Tyrväinen, L., Silvennoinen, H. \& Kolehmainen, O. (2003), 'Ecological and Aesthetic Values in Urban Forest Management', Urban Forestry \& Urban Greening, 1(3): 135-49. https://doi.org/10.1078/1618-8667-00014

Wang, Y., Sun, M. \& Song, B. (2017), 'Public Perceptions of and Willingness to Pay for Sponge City Initiatives in China', Resources, Conservation and Recycling, 122: 11-20. https://doi.org/10.1016/j.resconrec.2017.02.002

Williams, J.B., Jose, R., Moobela, C., Hutchinson, D.J., Wise, R. \& Gaterell, M. (2019), 'Residents' Perceptions of Sustainable Drainage Systems as Highly Functional Blue Green Infrastructure', Landscape and Urban Planning, 190: 103610. https://doi.org/10.1016/j.landurbplan.2019.103610

Woods Ballard, B., Wilson, S., Udale-Clarke, H., Illman, S., Scott, T., Ashley, R. \& Kellagher, R. (2015), CIRIA report C753 The SuDS Manual (London, CIRIA).

\section{Notes on the authors}

Dr Emily O'Donnell is a Research Fellow at the University of Nottingham, UK, specialising in urban flood resilience and water management, Blue-Green Cities, social learning, and stakeholder engagement. She is interested in how cities are addressing current and future urban water challenges associated with climate change.

Recent relevant publications:

O’Donnell, E. \& Thorne, C. (2020), 'Drivers of Future Urban Flood Risk', Philosophical Transactions of the Royal Society A, 378: 20190216. .https://doi.org/10.1098/rsta.2019.0216

O'Donnell, E., Maskrey, S., Everett, G. \& Lamond, J. (2020a), 'Developing the Implicit Association Test to Uncover Hidden Preferences for Sustainable Drainage Systems', Philosophical Transactions of the Royal Society A, 378: 20190207. .https://doi.org/10.1098/rsta.2019.0207

Corresponding author: emily.o'donnell@nottingham.ac.uk 
Simon Gosling is Professor of Climate Risks and Environmental Modelling at the University of Nottingham, UK. His research interests span the remit of understanding the impacts of future climate change on society, including understanding the importance of climate change adaptation and mitigation, from global to local scales. He specialises in understanding climate risks for freshwater resources, including flood risk and water availability, and he also has interests in risks to human health, labour productivity, food security, infrastructure, and the economy. In addition, he regularly engages in knowledge integration and knowledge exchange activities on climate change.

Recent relevant publications:

Feyen, L., Gosling, S.N. Ibarreta, D., Soria, A. \& Ciscar, J.C. (2020), Climate Change Impacts and Adaptation in Europe, JRC PESETA IV final report (Luxembourg, Publications Office of the European Union).

Schewe, J., Gosling, S.N., et al. (2019), 'State-of-the-art Global Models Underestimate Impacts from Climate Extremes', Nature Communications, 10: 1005. https://doi.org/10.1038/s41467-019-08745-6

Thompson, J.R., Gosling, S.N., Zaherpour, J. \& Laizé, C.L.R. (2021), 'Increasing Risk of Ecological Change to Major Rivers of the World with Global Warming', Earth's Future, 9:e2021EF002048. https://doi.org/10.1029/2021EF002048

simon.gosling@nottingham.ac.uk

Noelwah R. Netusil is the Stanley H. Cohn Professor of Economics at Reed College, US. She specialises in using nonmarket valuation techniques to study urban environmental issues such as flooding and stormwater management.

Recent publications:

Ando, A.W., Cadavid, C.L., Netusil, N.R. \& Parthum, B. (2020), 'Willingness-to-volunteer and Stability of Preferences Between Cities: Estimating the Benefits of Stormwater Management', Journal of Environmental Economics and Management, 99: 1-15. https://doi.org/10.1016/j.jeem.2019.102274

Netusil, N.R., Moeltner, K. \& Jarrad, M. (2020), 'Floodplain Designation and Property Sale Prices in an Urban Watershed', Land Use Policy, 88(C): 104-22. https://doi.org/10.1016/j.landusepol.2019.104112

Netusil, N.R., Jarrad, M. \& Moeltner, K. (2019), 'The Effect of Stream Restoration Project Attributes on Property Sale Prices', Landscape and Urban Planning, 185: 158-62. https://doi.org/10.1016/j.landurbplan.2019.02.002

https://orcid.org/0000-0002-0806-1153

netusil@reed.edu

Dr Faith Ka Shun Chan is an Associate Professor at the University of Nottingham Ningbo China. He specialises in sustainable flood risk management, climate adaptations, and urban resilience on Asian coastal megacities.

Recent publications:

Griffiths, J., Chan, F.K.S., Shao, M., Zhu, F. \& Higgitt, D.L. (2020), 'Interpretation and Application of Sponge City Guidelines in China', Philosophical Transactions of the Royal Society A, 378: 20190222. https://doi.org/10.1098/rsta.2019.0222 
Chan, F.K.S., Griffiths, J.A., Higgitt, D., Xu, S., Zhu, F., Tang, Y-T., Xu, Y. \& Thorne, C (2018), "Sponge City" in China-A Breakthrough of Planning and Flood Risk Management in the Urban Context', Land Use Policy, 76: 772-8. https://doi.org/10.1016/j.landusepol.2018.03.005

https://orcid.org/0000-0001-6091-6596

faith.chan@nottingham.edu.cn

Mr Nanco Dolman is a leading professional in Water Resilient Cities at Royal HaskoningDHV, Netherlands. From 2011 to 2016 he was a part-time lecturer in Adaptive Urban Development at the Rotterdam University of Applied Sciences. Internationally recognised as front runner in Water Sensitive Urban Design (WSUD), Nanco specialises in bridging water resilient design and engineering. Currently he is the Water Sensitive City expert for the EU Interreg funded research-project $\mathrm{CATCH}$; 'water sensitive Cities: the Answer To CHallenges of extreme weather events', in the North Sea Region.

Recent publications:

Özerol, G., Dolman, N., Bormann, H., Bressers, H., Lulofs, K. \& Böge, M. (2020), 'Urban Water Management and Climate Change Adaptation: A Self-assessment Study by Seven Midsize Cities in the North Sea Region', Sustainable Cities and Society, 55: 102066. https://doi.org/10.1016/j.scs.2020.102066

Dolman, N. \& Ogunyoye, F. (2018), 'How Water Challenges Can Shape Tomorrow's Cities', Proceedings of the Institution of Civil Engineers-Civil Engineering, 171: 2-30. https://doi.org/10.1680/jcien.17.00052

https://orcid.org/0000-0002-8134-6307

nanco.dolman@rhdhv.com

To cite the article: Emily C. O'Donnell, Simon N. Gosling, Noelwah R. Netusil, Faith Ka Shun Chan and Nanco J. Dolman (2021), 'Perceptions of blue-green and grey infrastructure as climate change adaptation strategies for urban water resilience', Journal of the British Academy, 9(s9): 143-182.

DOI https://doi.org/10.5871/jba/009s9.143

Journal of the British Academy (ISSN 2052-7217) is published by

The British Academy, 10-11 Carlton House Terrace, London, SW1Y 5AH

www.thebritishacademy.ac.uk 


\section{Appendices}

\section{Appendix 1 \\ Feeling thermometers investigating how safe, attractive, tidy (or maintained in the US version), useful, valuable, and necessary respondents believe blue-green infrastructure is.}

N.B. The same six feeling thermometers were used to investigate explicit perceptions of grey infrastructure, substituting 'blue-green' with 'grey' infrastructure.

Please indicate on the feeling thermometers how 1) safe, 2) attractive, 3) tidy, 4) useful, 5) valuable and 6) necessary you feel blue-green infrastructure is. Please click anywhere on the feeling thermometer to activate the slider, and then drag the slider to the point that best reflects your feelings.

1. Please indicate on the feeling thermometer how safe you feel blue-green infrastructure is.

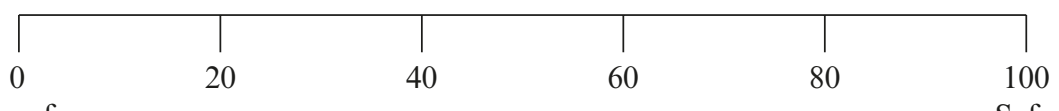

Unsafe Safe

Prefer not to answer

2. Please indicate on the feeling thermometer how attractive you feel blue-green infrastructure is.

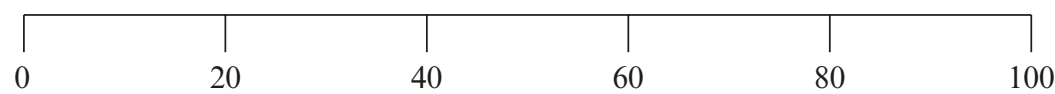

Unattractive

Attractive

O Prefer not to answer

3. Please indicate on the feeling thermometer how tidy you feel blue-green infrastructure is.

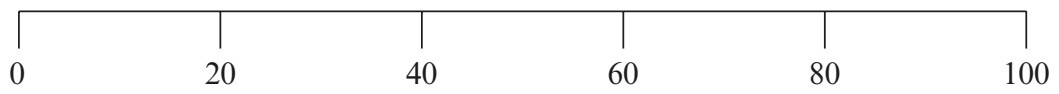

Untidy/unmaintained

Tidy/maintained

O Prefer not to answer

4. Please indicate on the feeling thermometer how useful you feel blue-green infrastructure is.

\begin{tabular}{|c|c|c|c|c|}
\hline & 1 & $\mid$ & 1 & 1 \\
\hline 0 & 20 & 40 & 60 & 80 \\
\hline
\end{tabular}

Prefer not to answer 
5. Please indicate on the feeling thermometer how valuable you feel blue-green infrastructure is.

\begin{tabular}{|c|c|c|c|c|c|}
\hline & d & 1 & $\mid$ & $\mid$ & ] \\
\hline $\begin{array}{c}0 \\
\text { va }\end{array}$ & 20 & 40 & 60 & 80 & $\begin{array}{c}100 \\
\text { Valuable }\end{array}$ \\
\hline
\end{tabular}

6. Please indicate on the feeling thermometer how necessary you feel blue-green infrastructure is for flood risk and stormwater management:

\begin{tabular}{|c|c|c|c|c|c|}
\hline & t & $T$ & 1 & | & \\
\hline 0 & 20 & 40 & 60 & 80 & $\begin{array}{c}100 \\
\text { Necessary }\end{array}$ \\
\hline
\end{tabular}

\section{Appendix 2 \\ Implicit Association Test (IAT): blue-green vs. grey infrastructure}

Information presented to respondents prior to competing the IAT, followed by the stages of the IAT, and an example where the IAT score is presented and explained.

You will be presented with sets of words to classify into groups using the 'E' and 'I' keys on the keyboard.

Positive words

Negative words

Blue-green infrastructure

Grey infrastructure
Attractive, Clean, Healthy, Reliable, Safe, Useful, Valuable

Dangerous, Dirty, Ugly, Unhealthy, Unreliable, Useless, Worthless

Green roof, Green wall, Retention pond, Rain garden, Street tree, Swale, Wetland

Combined sewer overflow, Culvert, Sewer, Storm drain, Subsurface pipe, Underground storage tank, Storm sewer

Tips for completing the IAT:

- Two labels at the top will tell you which words or images go with each key.

- Keep your index fingers on the 'E' and 'I' keys to enable rapid response.

- Each word has a correct classification. If you classify the word incorrectly a red 'X' will appear and you will need to press the correct key to move on.

- The test uses response times so please try to respond as fast as possible. 


\section{IAT stage 1}

Blue-green

- Keep your index fingers on the $\mathbf{E}$ and I keys of your keyboard.

- Words or images representing the categories at the top will appear one-by-one in the middle of the screen.

- When the item belongs to the category on the left, press the $\mathbf{E}$ key; when the item belongs to the category on the right, press the I key.

- Items belong to only one category.

- If you make an error, an $\mathbf{X}$ will appear. Fix the error by hitting the other key.

Press the space bar to begin Stage 1.

If the $\mathbf{E}$ and $\mathbf{I}$ keys do not work, click the mouse inside the white box and try again.

\section{IAT stage 2}

Positive words

Negative words

- Keep your index fingers on the $\mathbf{E}$ and I keys of your keyboard.

- If you make an error, an $\mathbf{X}$ will appear. Fix the error by hitting the other key.

Press the space bar to begin Stage 2.

If the $\mathbf{E}$ and $\mathbf{I}$ keys do not work, click the mouse inside the white box and try again.

\section{IAT stage 3}

Blue-green

or

Positive words

- Keep your index fingers on the $\mathbf{E}$ and I keys of your keyboard.

- If you make an error, an $\mathbf{X}$ will appear. Fix the error by hitting the other key.

Press the space bar to begin Stage 3.

If the $\mathbf{E}$ and $\mathbf{I}$ keys do not work, click the mouse inside the white box and try again. 


\section{IAT stage 4}

\section{Grey}

- Keep your index fingers on the $\mathbf{E}$ and I keys of your keyboard.

- If you make an error, an $\mathbf{X}$ will appear. Fix the error by hitting the other key.

Press the space bar to begin Stage 4.

If the $\mathbf{E}$ and $\mathbf{I}$ keys do not work, click the mouse inside the white box and try again.

\section{IAT stage 5}

Grey

Blue-green

or or

Positive words Negative words

- Keep your index fingers on the $E$ and I keys of your keyboard.

- If you make an error, an $\mathbf{X}$ will appear. Fix the error by hitting the other key.

Press the space bar to begin Stage 5.

If the $\mathbf{E}$ and $\mathbf{I}$ keys do not work, click the mouse inside the white box and try again.

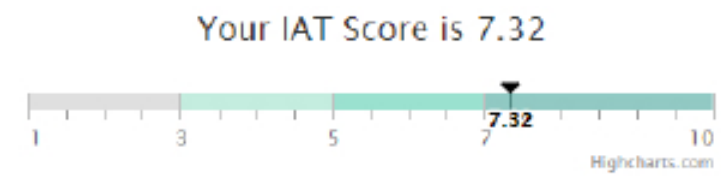

Your IAT score suggests that you have a preference for Blue-green infrastructure.

\section{Information on Implicit Association Tests}

The IAT software automatically calculates your implicit (subconscious) preference for bluegreen or grey drainage infrastructure based on the speed of your response to the IAT questions and pairing of blue-green or grey, and positive or negative, words. Pairings with faster responses and fewer errors are interpreted as more strongly associated in memory than more difficult pairings (slower responses).

We are interested in comparing your implicit preference with your explicit preference. We can determine this from your responses to the slider bars. Unfortunately, we are not able to report your explicit preferences in real time as the scores need to be calculated off-line. However, we will email your explicit preference to you once this has been calculated. 
The spontaneous nature of implicit association tests removes many of the external influences associated with measuring explicit attitudes, and negates issues of social desirability bias, self-enhancement bias, and self-ignorance bias common with explicit tests. IATs have been used to investigate a range of attitudes, including nuclear power (e.g. Truelove et al., 2014) and climate change (Beattie and McGuire, 2012), carbon footprint products (Beattie and Sale, 2009), connections with nature (Bruni and Schultz, 2010), GM foods (Spence and Townsend, 2006) and racial prejudices (e.g. Greenwald et al., 1998).

For more information on the Blue-Green Futures project please see our project blog or contact one of the project team:

Emily O'Donnell and Simon Gosling, University of Nottingham UK

Noelwah Netusil, Reed College, Portland Oregon USA

Faith Chan, University of Nottingham Ningbo China

Nanco Dolman, Royal HaskoningDHV, Amsterdam the Netherlands

References:

- Beattie, G. and McGuire, L. (2012) See no evil? Only implicit attitudes predict unconscious eye movements towards images of climate change. Semiotica 192, 315-339.

- Beattie, G. and Sale, L. (2009) Explicit and implicit attitudes to low and high carbon footprint products. International Journal of Environmental, Cultural, Economic and Social Sustainability 5, 191-206.

- Bruni, C.M. and Schultz, P.W. (2010) Implicit beliefs about self and nature: Evidence from an IAT game. Journal of Environmental Psychology 30, 95-102.

- Greenwald, A.G., McGhee, D.E. and Schwartz, J.L. (1998) Measuring individual differences in implicit cognition: the implicit association test. Journal of Personality and Social psychology 74, 1464.

- Spence, A. and Townsend, E. (2006) Implicit attitudes towards genetically modified (GM) foods: A comparison of context-free and context-dependent evaluations. Appetite 46, 67-74.

- Truelove, H.B., Greenberg, M.R. and Powers, C.W. (2014) Are implicit associations with nuclear energy related to policy support? Evidence from the brief implicit association test. Environment and Behavior 46, 898-923. 


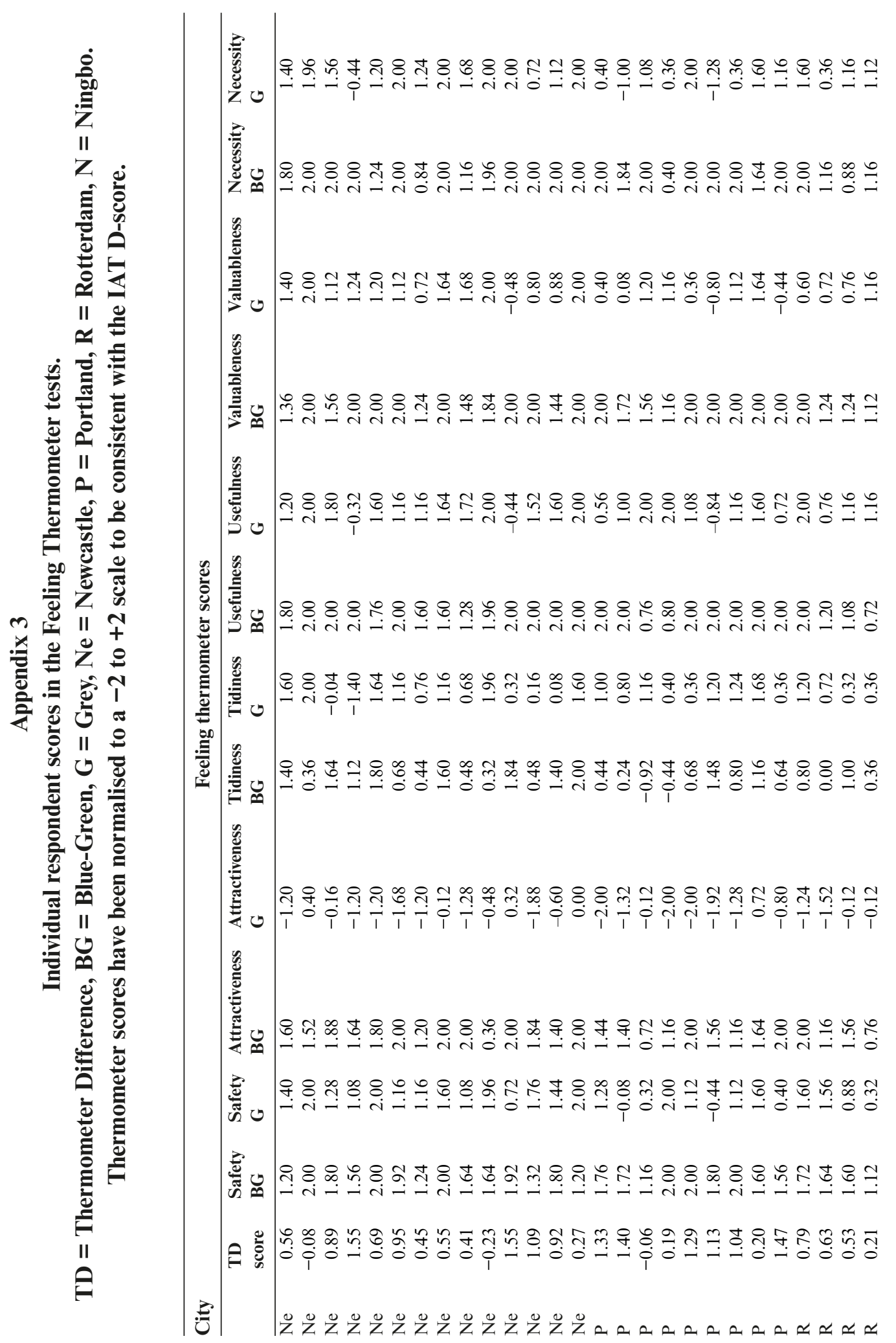




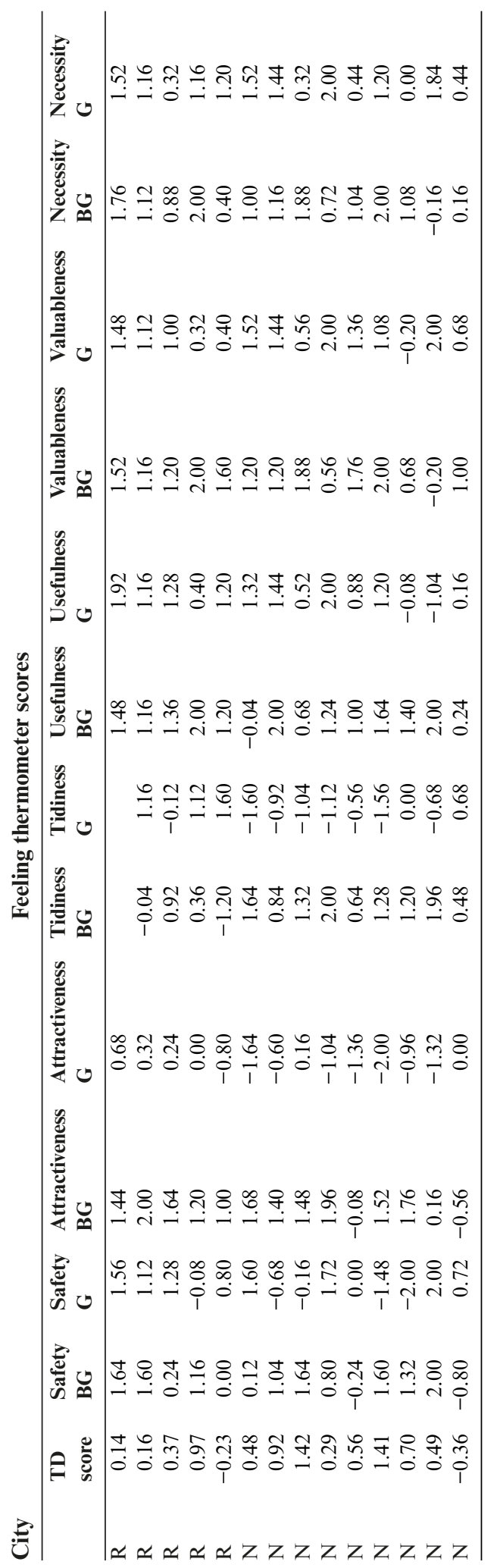




\section{Appendix 4}

Individual respondent scores in the Implicit Association Test (IAT).

\begin{tabular}{lc}
\hline City & IAT D-score \\
\hline Newcastle & 0.44 \\
Newcastle & 0.14 \\
Newcastle & 0.70 \\
Newcastle & 2.00 \\
Newcastle & 0.54 \\
Newcastle & 1.04 \\
Newcastle & 0.20 \\
Newcastle & 0.52 \\
Newcastle & 0.31 \\
Newcastle & 0.56 \\
Newcastle & 2.00 \\
Newcastle & 1.31 \\
Newcastle & 1.99 \\
Newcastle & 0.78 \\
Portland & 1.10 \\
Portland & 1.52 \\
Portland & 0.90 \\
Portland & 1.57 \\
Portland & 0.84 \\
Portland & 1.40 \\
Portland & 1.22 \\
Portland & -0.47 \\
Portland & 1.15 \\
Rotterdam & 0.20 \\
Rotterdam & 0.87 \\
Rotterdam & 0.62 \\
Rotterdam & 1.02 \\
Rotterdam & 1.49 \\
Rotterdam & 1.09 \\
Rotterdam & 1.07 \\
Rotterdam & 1.16 \\
Rotterdam & 1.18 \\
Ningbo & 0.47 \\
Ningbo & 0.48 \\
Ningbo & 0.53 \\
Ningbo & 0.27 \\
Ningbo & 1.26 \\
Ningbo & 0.75 \\
Ningbo & 0.80 \\
Ningbo & 0.74 \\
Ningbo & 0.84 \\
\hline & \\
\hline
\end{tabular}




\section{Appendix 5}

\section{Correlations between explicit attributes of Blue-Green Infrastructure (BGI) and Grey Infrastructure (feeling thermometer data).}

A Spearman's rank-order correlation was run to determine the relationships between the six attributes of BGI, and six attributes of grey infrastructure. Shaded cells represent correlations that are significant at the 0.05 level (2-tailed).

BGI

\begin{tabular}{|c|c|c|c|c|c|c|}
\hline & Safety & Attractiveness & Tidiness & Usefulness & Valuableness & Necessity \\
\hline Safety & & $\begin{array}{l}r=0.154 \\
p=0.669\end{array}$ & $\begin{array}{l}r=0.145 \\
p=0.372\end{array}$ & $\begin{array}{l}r=0.460 \\
p=0.002\end{array}$ & $\begin{array}{l}r=0.390 \\
p=0.012\end{array}$ & $\begin{array}{l}r=0.410 \\
p=0.008\end{array}$ \\
\hline Attractiveness & & & $\begin{array}{l}r=0.429 \\
p=0.006\end{array}$ & $\begin{array}{l}r=0.308 \\
p=0.052\end{array}$ & $\begin{array}{l}r=0.352 \\
p=0.024\end{array}$ & $\begin{array}{l}r=0.371 \\
p=0.017\end{array}$ \\
\hline Tidiness & & & & $\begin{array}{l}r=0.230 \\
p=0.154\end{array}$ & $\begin{array}{l}r=0.081 \\
p=0.620\end{array}$ & $\begin{array}{l}r=0.111 \\
p=0.492\end{array}$ \\
\hline Usefulness & & & & & $\begin{array}{l}r=0.610 \\
p=0.000\end{array}$ & $\begin{array}{l}r=0.657 \\
p=0.000\end{array}$ \\
\hline Valuableness & & & & & & $\begin{array}{l}r=0.816 \\
p=0.000\end{array}$ \\
\hline
\end{tabular}

\section{Grey Infrastructure}

\begin{tabular}{|c|c|c|c|c|c|c|}
\hline & Safety & Attractiveness & Tidiness & Usefulness & Valuableness & Necessity \\
\hline Safety & & $\begin{array}{l}r=0.004 \\
p=0.980\end{array}$ & $\begin{array}{l}r=0.305 \\
p=0.055\end{array}$ & $\begin{array}{l}r=0.567 \\
p=0.000\end{array}$ & $\begin{array}{l}r=0.576 \\
p=0.000\end{array}$ & $\begin{array}{l}r=0.462 \\
p=0.002\end{array}$ \\
\hline Attractiveness & & & $\begin{array}{l}r=0.194 \\
p=0.230\end{array}$ & $\begin{array}{l}r=0.178 \\
p=0.266\end{array}$ & $\begin{array}{l}r=0.173 \\
p=0.280\end{array}$ & $\begin{array}{l}r=0.188 \\
p=0.239\end{array}$ \\
\hline Tidiness & & & & $\begin{array}{l}r=0.291 \\
p=0.069\end{array}$ & $\begin{array}{l}r=0.071 \\
p=0.664\end{array}$ & $\begin{array}{l}r=0.205 \\
p=0.205\end{array}$ \\
\hline Usefulness & & & & & $\begin{array}{l}r=0.603 \\
p=0.000\end{array}$ & $\begin{array}{l}r=0.456 \\
p=0.003\end{array}$ \\
\hline Valuableness & & & & & & $\begin{array}{l}r=0.495 \\
p=0.001\end{array}$ \\
\hline
\end{tabular}




\section{Appendix 6}

Explicit preferences for Blue-green and Grey Infrastructure calculated using different selections of evaluative attributes.

\begin{tabular}{lll}
\hline Evaluative attributes & TD score & Range \\
\hline Safety, attractiveness, tidiness*, usefulness, & $0.66(0.52)$ & -0.36 to 1.55 \\
valuableness and necessity & & \\
Safety, attractiveness, tidiness* & $0.74(0.61)$ & -0.60 to 2.00 \\
Safety, attractiveness, tidiness*, necessity & $0.66(0.50)$ & -0.65 to 1.40 \\
Safety, tidiness*, necessity & $0.33(0.58)$ & -1.47 to 1.59 \\
\hline
\end{tabular}

Standard deviation is given in parentheses, $n=41$.

*Tidiness or maintained in the US tests, which is common vocabulary to describe the appearance of Blue-green Infrastructure. 